\title{
Microparticles in Cancer
}

\author{
Janusz Rak, M.D., Ph.D. ${ }^{1}$
}

\section{ABSTRACT}

Microparticles (MP) are vesicular structures released from cells upon activation, malignant transformation, stress, or death. MP may be derived from the plasma membrane (shed microvesicles), produced by endosomal pathway (exosomes), or arise from membrane blebs of apoptotic cells. The terms microparticles or microvesicles (MV) are often used as general and interchangeable descriptors of all cellular vesicles, but a more rigorous terminology is still to be established. The cargo of MP/MV consists of proteins, lipids, and nucleic acids (DNA, mRNA, microRNA), all of which may be transferred horizontally between cells. In cancer, oncogenic pathways drive production of MP/MV, and oncoproteins may be incorporated into the cargo of MV (oncosomes). Oncogenic pathways may also stimulate production of MP/MV harboring tissue factor and involved in cancer coagulopathy. In addition, the cargo of MV may include several receptors, antigens, bioactive molecules, and other species capable of stimulating tumor progression, immunotolerance, invasion, angiogenesis, and metastasis. MP emanate not only from tumor cells but also from platelets, endothelium, and inflammatory cells. Indeed, circulating MP/MV harbor molecular information related to cancer-related processes and may serve as a reservoir of prognostic and predictive biomarkers to monitor genetic tumor progression, angiogenesis, thrombosis, and responses to targeted therapeutics.

KEYWORDS: Microparticles, cancer, oncogenes, tissue factor, microvesicles, exosomes, coagulation, angiogenesis

\section{CELLULAR MICROPARTICLES AS UNITS OF BIOLOGICAL INFORMATION}

In a multicellular organism, biological functions are executed by assemblies of cells whose actions must be coordinated by intercellular communication. In this regard, the exchange of signals is usually ascribed to specific molecules (soluble or immobilized) and their corresponding cognate receptors. Such exchange may entail a direct cell-to-cell contact (adhesion, juxtacrine interactions) or release and gradient forming soluble (paracrine) mediators, which may also circulate in blood and body fluids and act in a regional or systemic (endocrine) manner. Such information translates into activation of intracellular signaling networks, ${ }^{1,2}$ in either one or two directions, ${ }^{3}$ thereby changing the cellular behavior. In addition to these canonical processes, a seemingly direct uptake of factors, enzymes, and particles has also been described in several instances and found to trigger rearrangements of the intracellular machinery. ${ }^{4-7}$ Numerous pathways of (uni)molecular intercellular communication have been characterized to date $^{8}$ and documented to act as important players in health and disease, including cancer. ${ }^{9-11}$

In addition to their participation in the intercellular networks of the (uni)molecular messages just mentioned, cells may also compose and receive more complex
${ }^{1}$ Montreal Children's Hospital Research Institute, McGill University, Montreal, Quebec, Canada.

Address for correspondence and reprint requests: Janusz Rak, M.D., Ph.D., Montreal Children's Hospital Research Institute, McGill University, 4060 Sainte Catherine West, Montreal, QC H3Z 2Z3, Canada (e-mail: janusz.rak@mcgill.ca).

Microparticles in Thrombosis and Hemostasis; Guest Editors,
Nigel S. Key, M.D., and Hau C. Kwaan, M.D., Ph.D.

Semin Thromb Hemost 2010;36:888-906. Copyright (C) 2010 by Thieme Medical Publishers, Inc., 333 Seventh Avenue, New York, NY 10001, USA. Tel: +1(212) 584-4662.

DOI: http://dx.doi.org/10.1055/s-0030-1267043.

ISSN 0094-6176. 
(multi)molecular signals, packaged in fragments of plasma membrane, or specialized extracellular organelles of a vesicular (microvesicles), ${ }^{12,13}$ tubular (nanotubes), ${ }^{14}$ or filopodial (cytoneme) $)^{15}$ nature. These structures serve to transmit their protein, lipid, or nucleic acid cargo through a process often referred to as trogocytosis, or cellular synapse. ${ }^{16,17}$ This mode of intercellular contact allows the transmission of both soluble and insoluble (e.g., membrane bound) entities, in a preprogrammed, combinatorial and efficient manner, and while protecting the signaling molecules from extracellular degradation. ${ }^{18}$ As in the case with soluble mediators, the vesicular material emitted by various cells may participate in short-, medium-, and long-range communication or in cellular defense and attack processes, whose nature and scope still remains to be understood in a far greater depth.

There is a marked biological diversity among cellular vesicles in terms of their origin, structure, function, and cargo. Therefore, several terms are used to describe them, including microparticles (MP), secretory vesicles (SV), microvesicles (MV), ectosomes (ECSM) or exosomes (EXSM), and many more, depending on the context in which they are studied and their particular properties. ${ }^{13,18-26}$ In this article we collectively refer to vesicles released from various cellular sources, including cancer cells, as microparticles (MP) or microvesicles $(\mathrm{MV})$, which are perhaps the most commonly used terms at the moment but not necessarily the most precise. Indeed, in this area a wider consensus as to the nomenclature is still to be reached. ${ }^{13}$ Examples of confusing differences in the usage of various terms include description as microvesicles (MV), as either a more general and all-encompassing descriptor of all vesicles, microparticles, and exosomes ${ }^{23,26}$ or in a more circumscribed manner. In the latter case, MV are described as plasma membrane-derived structures produced by viable cells, and often referred to as ectosomes. ${ }^{19}$ Still, in other publications, microparticles (MP) are viewed mainly as products of cellular apoptosis, ${ }^{27}$ and there are sources in which this term is used interchangeably with $M V$ and ECSM. ${ }^{26}$ Because different studies use different criteria to describe various microvesicles, their comparisons may be difficult and the nomenclature often inconsistent.

Differences among various MV/MP in terms of their nature and nomenclature may, to some extent, be derived from their cellular sources. In this regard some studies examined circulating MP for lineage/tissue-specific markers to pinpoint their cells of origin. This resulted in the description of distinct MP emanating from platelets (PMP), monocytes (MMP), endothelial cells (EMP), or tumor cells (TMP), which exhibit both similarities and differences. ${ }^{20,26,28-31}$ The differential nomenclature of MP may also result from traditions adopted by different research fields, in which processes of cellular vesiculation have been studied in different ways, often somewhat independently from one another. This distinctiveness was attached to procoagulant and regulatory MP that emerged relatively early from studies on hemostasis and vascular biology. ${ }^{26,30,32-35}$ In contrast, MV were studied in the field of neurobiology and immunomodulation, ${ }^{13,36,37}$ and EXSM have entered the scene largely in the course of studies on cellular differentiation, ${ }^{19}$ endosomal trafficking and receptor recycling. ${ }^{38-40}$ What adds to the confusion is that the term exosome has also been used to describe the intracellular ribonuclease complex, which is completely unrelated to cellular vesiculation. ${ }^{41}$

Nonetheless, MP/MV have emerged as a long known but newly appreciated mode of biological regulation, and they are increasingly implicated in various important contexts, especially during vascular pathology, immune responses, cellular differentiation, and other physiologically and pathologically significant events. ${ }^{42-}$ 45 Their role is also increasingly recognized in cancer, including in such aspects of the disease as cancer coagulopathy, ${ }^{26,30,34,46-50}$ activated stroma generation, ${ }^{51}$ tumor growth, ${ }^{22}$ establishment of the tumor stem cell niche, ${ }^{49}$ invasion, ${ }^{52}$ angiogenesis, ${ }^{53-58}$ metastasis, ${ }^{54,59-61}$ and immune responses/evasion. ${ }^{12,23,58,62-66}$ Moreover, distinct molecular properties of MP present in the bloodstream and body fluids of cancer patients render them potentially useful as a novel and unique source of diseaserelated information. ${ }^{23,62,67,68}$ Although this area still remains to be explored more fully (e.g., as a source of biomarkers), a considerable demand for such markers reflecting the natural complexity does seem to exist in terms of individualized patient care, precise molecular diagnosis, and monitoring the effects of targeted therapies. ${ }^{18}$ The crucial questions that perhaps should be addressed before MV/MP are fully understood and utilized are those surrounding their biogenesis, biological roles, and their functional involvement in the pathogenesis of cancer and other diseases.

\section{BIOGENESIS OF MICROPARTICLES}

The properties of various MP are implicitly defined by their biogenesis. Cellular vesiculation has been appreciated and studied for several decades, but its exact mechanisms still remain surprisingly mysterious. ${ }^{20}$ Indeed, the release of vesicular organelles was first described by Wolf in 1967, who noted formation of a particulate "dust" by activated blood platelets. ${ }^{33}$ In a series of pioneering studies Johnstone observed that seemingly similar organelles (EXSM) were produced by differentiating reticulocytes, and were involved in the removal of "spent" transferrin receptors from the emerging red blood cells. ${ }^{19}$ Formation of vesicles was also noticed in the case of cancer cells, in which their cargo was found to contain procoagulant mediators such as tissue factor (TF) ${ }^{34}$ and, more recently, mucins 
Table 1 Oncogenic Induction of Cellular Vesiculation

\begin{tabular}{|c|c|c|}
\hline Oncogenic Pathway & Impact on Vesiculation & Reference \\
\hline K-ras & $\begin{array}{l}\text { Increased emission of TF-containing procoagulant microvesicles in colorectal } \\
\text { cancer cells expressing mutant K-ras }\end{array}$ & Yu et $\mathrm{al}^{74}$ \\
\hline EGFRvIII & $\begin{array}{l}\text { Increase in vesiculation and incorporation of EGFRvIll into microvesicles } \\
\text { (oncosomes) in glioma cells transformed with this oncogene }\end{array}$ & Al-Nedawi et $a^{23}$ \\
\hline p53 & $\begin{array}{l}\text { Increase in production of TF-containing microvesicles in colorectal cancer } \\
\text { cells upon deletion of p53 gene }\end{array}$ & Yu et $a l^{74}$ \\
\hline p53 & $\begin{array}{l}\text { Increase in exosome production in cells, in which irradiation triggered } \\
\text { p53 expression }\end{array}$ & Yu et $\mathrm{al}^{75}$ \\
\hline EGFR/AKT & $\begin{array}{l}\text { Activation of the EGFR and AKT pathways stimulated vesiculation of } \\
\text { prostate cancer cells }\end{array}$ & Di Vizio et $a^{28}$ \\
\hline
\end{tabular}

TF, tissue factor; EGFRvIII, epidermal growth factor receptor variant III; EGFR, epidermal growth factor receptor.

(MUC1). ${ }^{29}$ These intriguing observations were subsequently extended to several other characteristics and linked to cancer-related biological events. ${ }^{12,13,19}$ The association of MP production in the context of cancer is increasingly recognized ${ }^{12,13,18,19,25,26,69}$ and raises numerous questions as to the implications, regulation, and molecular mechanisms of the underlying processes.

Biogenesis of MP/MV (vesiculation) is not unique to cancer and occurs during such processes as cellular differentiation, stress, activation, senescence, ${ }^{70}$ stimulation with cytokines or shear force, ${ }^{12}$ exposure to adenosine triphosphate (ATP), ${ }^{71}$ apoptotic cell death, ${ }^{27}$ changes in the microenvironment, ${ }^{72}$ hypoxia, ${ }^{73}$ and malignant transformation. ${ }^{34}$ In the latter case, the action of mutant oncogenes, such as $\mathrm{K}-$ ras $^{74}$ and epidermal growth factor receptor (EGFR), ${ }^{23}$ or its mutant, called EGFR variant III (EGFRvIII), appear to stimulate the release of MP (MV) in increased quantities (Table 1). Similarly, the activation ${ }^{75}$ or $\operatorname{loss}^{74}$ of certain tumor suppressors (e.g., p 53) $)^{74}$ appears to impact cellular vesiculation. These examples likely capture only a small fragment of the oncogenic regulation of cellular vesiculation, either alone or in concert with various influences of the tumor microenvironment. ${ }^{18}$ Interestingly, oncoproteins not only stimulate formation of MP/MV, but also become their cargo, a process described as formation of oncosomes. ${ }^{22,23}$ Moreover, oncosomes may serve as a vehicle whereby oncogenic cargo may be transferred horizontally between cells, both transformed and nontransformed. ${ }^{22,23}$

Pathways mediating oncogene-dependent vesiculation are still somewhat obscure, but their elements are gradually coming to light. For instance, a recent elegant report by Di Vizio et $\mathrm{al}^{28}$ suggested that MP production by prostate cancer cells could involve the activation of the Akt pathway and loss of the actin nucleating protein known as diaphanous-related formin 3 (DRF3/Dia2). Because DRF3 expression is lost during the development of metastatic disease, more aggressive prostate cancer cells may become increasingly prone to undergo vesiculation and to releasing active signaling proteins into their surroundings via oncosomes. ${ }^{28}$ These processes may also involve Src activity. ${ }^{71}$ Interestingly, Arf6, a small GTPase involved in cancer cell invasion, has been shown to promote shedding of proteolytic and proinvasive MV/ MP from several types of transformed cells. ${ }^{76}$ It is very likely that many additional molecular pathways could be involved as well. Their effects may resemble those involved in cancer-unrelated forms of vesiculation, including calcium fluxes, cortical actin reorganization, altered lipid metabolism, as well as many others. ${ }^{35}$

One important and poorly understood aspect of cellular vesiculation has to do with the assembly of the MP/MV cargo. Interestingly, studies on the proteomes of MP/MV reveal both similarities and differences vis-àvis the protein expression profiles of the corresponding cells of origin. ${ }^{62,77,78}$ The underlying molecular sorting mechanisms are probably quite diverse, and they are studied more in the case of certain types of MV/MP (e.g., EXSM) ${ }^{38}$ than in other instances. It is believed that the cargo of MP may be related to the dynamics of plasma membrane domains, from which vesicles originate (e.g., formation of lipid rafts), ${ }^{46}$ but what controls the content of the MV lumen is less understood. Clearly, the nature of the cell of origin is an important factor in these processes because membrane antigens of endothelial cells, platelets, and other cells are often also found on the surfaces of their corresponding MV/MP. ${ }^{13,30}$ The functional state of cells (e.g., activation) also impacts the cargo of $\mathrm{MP},{ }^{23}$ as does the specific type of MP being generated and their history post release. For instance, the composition of MP may change as a result of their possible fusion with other, even heterologous MP. ${ }^{29}$ Also, secondary vesiculation events involving material from nonsecretory intracellular vesicles recruited to the plasma membrane $^{20}$ and plausible reemission of the material previously transferred from other cells may contribute to the MP/MV composition. Although the lineage markers are often used to establish the origin of $M P,{ }^{25,30}$ the vesicle-associated protein, mRNA, and microRNA cargo may also differ considerably from that of the emitting cells. ${ }^{62,77}$ In the case of PMP, the most abundant MP circulating in the peripheral blood, their 
procoagulant cargo is concentrated up to two orders of magnitude as compared with the corresponding membranes of intact platelets. ${ }^{79}$ This may suggest the existence of mechanisms that control a selective (rather than random) loading of the MP with certain types of cargo. It is plausible that in the case of cancer cells this loading process could be influenced by the underlying repertoire of cellular/genetic and signaling aberrations. ${ }^{18}$

\section{PROCESSES UNDERLYING BIOLOGICAL HETEROGENEITY OF CELLULAR MICROPARTICLES}

MP studied in different experimental settings have been distinguished from one another by several features. Their diverse origin, as well as molecular and morphological characteristics, led to the emergence of the elaborate nomenclature, including terms such as tumor vesicles, cellular vesicles, shedding vesicles, microvesicles, microparticles, exosomes, ectosomes, enlargeosomes, promininosomes, prostasomes, epididimosomes, argosomes, archeosomes, or oncosomes. ${ }^{13,19,20,23,80}$ As mentioned earlier, some of these terms are used interchangeably with others or more exclusively, but not always, with the necessary consistency. ${ }^{19}$ The concepts as to what exactly distinguishes different vesicles, and to what extent, also vary considerably. For instance, recent studies pointed to similarities in compositions between vesicles (EXSM) of different cellular origin including glioma cells. Such tumor-derived EXSM would mainly differ from their normal counterparts by harboring oncogenic receptors. ${ }^{81}$ Other studies focus on diversity of MV/MP and highlight the distinct molecular makeup of their different subsets, ${ }^{62,77}$ even if they emanate from the same cellular source. $^{82}$

Indeed, heterogeneity among $\mathrm{MP} / \mathrm{MV}$ is probably rather common. For instance, it is difficult to imagine that dramatic differences between cancer cells originating from different tissues would result in production of similar MV. Likewise, different genetic and microenvironmental influences affecting cancer cells would be expected to produce not only quantitative $e^{23,74}$ but also qualitative differences ${ }^{18,81}$ between MV being generated. ${ }^{18}$ Moreover, different stimuli modulating the responses of normal cells associated with various cancers would likely change the profile of MP emanating from tumor stroma. ${ }^{20}$ Some of these differences could be informative as to the pathogenesis of the underlying malignant process and thereby potentially useful for prognostic, predictive, or therapeutic purposes. ${ }^{18}$ Perhaps most importantly, it is very unlikely that fundamentally different mechanisms of cellular vesiculation that could coincide in the same or different cells would lead to formation of uniform or otherwise similar vesicular structures, especially in changing disease settings. It is also possible that with progression of the same disease the underlying molecular processes and cellular diversification would produce changing patterns of MP/MV emission into the tissue and systemic circulation. In this regard, there are presently at least three different known major pathways that lead to emission of cellular vesicles, namely (1) through apoptotic cellular breakdown, leading to formation of apoptotic bodies, sometimes referred to as true microparticles; ${ }^{83}$ (2) vesiculation associated with processes of plasma membrane blebbing and shedding; and (3) endocytosis-related formation of EXSM. $^{12,13,19,84}$ It is very likely that additional variations of these mechanisms may exist, leading to the emission of the heterogenous repertoire of MP. ${ }^{82}$ The details of these distinct vesiculation processes are worthy of some commentary.

\section{Apoptotic Microparticles}

Formation of apoptotic MP represents a terminal consequence of membrane blebbing and cell fragmentation in the course of the classical programmed cell death. ${ }^{85}$ An interesting consequence of this chain of events is that the resulting MP may continue to "posthumously" propagate some of the cellular material from their already nonexistent cells of origin, including their DNA fragments containing transforming genomic sequences. ${ }^{86,87}$ It may be possible to recover these sequences from circulating apoptotic MP found in the blood of cancer patients. ${ }^{88}$ Because formation of apoptotic MP effectively ends the existence of their cellular sources, the significance of these MP may be transient, unless the process of cell division, death, and apoptotic vesiculation occurs in a perpetual manner (e.g., in certain cancers).

\section{Membrane Microvesicles}

$\mathrm{MP} / \mathrm{MV}$ are also generated by viable cells, often for extended periods of time, and especially upon their activation or transformation. ${ }^{18}$ This occurs through the outward blebbing of the plasma membrane regions, ${ }^{13,19,89}$ which gives rise to relatively large structures ( $>100 \mathrm{~nm}$ up to $1000 \mathrm{~nm}$ in diameter), often referred to as bona fide MP, MV, ${ }^{13}$ shedding, or membrane (micro)vesicles. ${ }^{20}$ It has been suggested that such MP emanate preferentially from membrane lipid rafts, a notion consistent with their high content of raft-related proteins such as flotilin-1, $\mathrm{TF},{ }^{46,74}$ certain cellular lineage markers, ${ }^{35}$ and, in some cases, oncogenic growth factor receptors, such as EGFR. ${ }^{23}$ Such MV may exhibit high levels of exposed phosphatidylserine (PS), integrins (e.g., $\beta 1$, and metalloproteinases. ${ }^{31}$ They may also express Pselectin glycoprotein ligand (PSGL)1 (e.g., in the case of macrophages) or contain cytokines and chemokines, such as interleukin (IL)1 $\beta$, vascular endothelial growth factor (VEGF), fibroblast growth factor (FGF)2, regulated 
upon activation, normal T-cell expressed and secreted (RANTES), and other cargo. ${ }^{31,58,90-92}$

The mechanism of this mode of (exo/ecto)vesiculation entails a focal and temporary change in the state of the enzymatic apparatus that maintains the "tonic" asymmetry of plasma membrane phospholipids. ${ }^{35}$ This energy-dependent mechanism ensures that phosphatidylcholine and sphingomyelin (SM) remain on the outer surface of the plasma membrane while PS and phosphatidylethanolamine are exposed intracellularly. ${ }^{35}$ Such action may be executed by the set of calcium-responsive, lipid-translocating enzymes (flippases), the cluster of which required for vesiculation usually includes gelsolin (expressed mainly in platelets), aminophospholipid translocase, lipid scramblase, floppase, and calpain. ${ }^{35,93}$ The release of cytosolic calcium causes profound changes in the state of these enzymes resulting in the inactivation of lipid translocase and activation of scramblase. This is followed by externalization of PS and changes in the membrane geometry, blebbing, and altered cytoskeletal interactions, all of which lead to the formation and eventual release of a "mature" $\mathrm{MP} / \mathrm{MV} .^{35}$

The process of MP/MV generation may be activated by ATP and the related receptors (especially $\mathrm{P} 2 \mathrm{X} 7^{90}$ ), for example, upon the exposure of susceptible cells to the material released from their dying neighbors. This stimulation leads to mobilization of acidic sphingomyelinase (A-SMAse) and the resulting membrane phospholipid rearrangement. In the case of glial cells, this mechanism was found to be essential for microvesicular release of IL- $1 \beta$ This process may stimulate inflammatory responses, which are thought to help remove the dying cells (a source of the ATP). ${ }^{71}$ Formation of microvesicles may occur more readily at plasma membrane sites containing a high abundance of cholesterol (e.g., membrane lipid rafts). ${ }^{46}$ Unlike apoptotic bodies, such membrane raft-related MP do not contain cellular organelles, nuclear material, or DNA fragments. ${ }^{94}$

Physical events and mechanical forces leading to vesiculation are poorly understood. It is thought that the changes just mentioned in the phospholipid bilayer organization and the exposure of PS on the cell surface are linked with the formation of a localized physical "bend" of the plasma membrane. This is followed by a growing protrusion (blebbing), ${ }^{95,96}$ eventually leading to MP maturation and release. Proteins have also been implicated in the formation of such membrane curvatures, acting in an either enzymatic or nonenzymatic manner. ${ }^{97}$ Expansion of the membrane protrusions and disruption of the membrane-cytoskeletal connections is, at least in part, catalyzed by gelsolin and calpain, which contribute to the eventual shedding of the emerging $\mathrm{MP} / \mathrm{MV} .{ }^{35}$ Moreover, these events could involve not only physical forces inherent to the emerging structures but also applied by contractile proteins that have been found in both mature MP/
MV and in the "necks" or membrane protrusions before MP/MV shedding. ${ }^{76}$ Because the emission of MP by activated cells leads to the loss of membrane material, the nonsecretory intracellular vesicles are thought to be mobilized to the cell surface. As they replenish the membrane lipids, they too could form MP and be shed to the pericellular microenvironment, thereby changing the repertoire of the emitted MP over time..$^{20}$ For various reasons the repertoire of circulating MP may also change at the systemic level, for example, as a function of gender, ${ }^{98}$ circadian rhythm, ${ }^{99}$ health status, ${ }^{30}$ possibly cancer progression, and other factors.

Interestingly, aberrant microvesiculation is associated with certain hereditary conditions, such as Scott's syndrome, Castaman's syndrome, and possibly also Stormorken's syndrome. ${ }^{30}$ These states are often manifested by bleeding propensities, suggesting that the impact of abnormal vesiculation on platelets is the most immediate (albeit not a sole) manifestation of the underlying defects. ${ }^{35}$ Perhaps the best described in this regard is Scott's syndrome, where the impaired activity of the lipid scramblase leads to the inability of blood platelets to expose PS and to produce procoagulant MP ${ }^{35,100}$ Curiously, mice deficient in phospholipid scramblase 1 are hemostatically normal but instead develop defects in hematopoiesis. ${ }^{101}$ This reveals a possible nonhemostatic role of $\mathrm{MP}^{18,45}$ (or scramblase), raises questions as to the identity of MP-associated scramblase, and enforces the notion that mouse models may not always capture all the relevant aspects of human disease. ${ }^{102}$ With this qualification, it is interesting to note that pharmacological blockade of PS, for example, by systemic injections of the annexin $\mathrm{V}$ analog (Diannexin), has shown some anticancer activity in mouse models, ${ }^{18,22,103}$ possibly due to inhibition of microvesicular interactions ${ }^{23}$ required for angiogenesis.

\section{Exosomes}

A fundamentally distinct form of vesiculation is involved in the biogenesis of EXSM. ${ }^{12,13,18-20,39,49,65}$ Indeed, generation of these unique small MV occurs via the pathway of endocytosis rather than through a direct protrusion of the cellular plasma membrane. ${ }^{38}$ In the case of EXSM, the initial budding of the plasma membrane occurs inward, at sites containing signaling receptor tyrosine kinases, whose recycling and regulation this mechanism controls. ${ }^{38}$ The following evolution of vesicular structures is controlled by the endosomal sorting complex required for transport (ESCRT) system, ${ }^{38,104} \mathrm{a}$ set of multimolecular conglomerates responsible for the formation of the plasma membrane regions, in which the molecular cargo is processed for internalization. This entails tagging by ubiquitination and incorporation into inward budding regions of the plasma membrane. ${ }^{38,105}$ The resulting caveolae, or coated pits, develop into 
intracellular vesicles known as early endosomes. Cellular receptors present within endosomes may retain signaling activity but are ultimately destined for recycling or lysosomal degradation. ${ }^{105}$

During these processes early endosomes are transformed into more complex structures, known as multivesicular bodies (MVB), and late endosomes ${ }^{38}$ which evolve within the cytosol under the control of the ESCRT system. This leads to MVB fusion with lysosomes, where their cargo undergoes proteolytic destruction. ${ }^{38}$ Alternatively, endosomal cargo may be recycled to the plasma membrane. ${ }^{13,38}$ A third pathway associated with the endosomal system triggers a secondary inward membrane budding process within MVB, which results in formation of smaller intraluminal vesicles (ILV). ILV contain phospholipid capsule containing transmembrane receptors, which exhibit the outsideout orientation. ${ }^{13,40,104}$ A fascinating process of lipid self-assembly has recently been described to explain the formation of ILV ("pre-exosomes"). ${ }^{104}$ In an elegant study Trajkovic et al demonstrated a spontaneous formation of small EXSM-like structures within synthetic larger lipid vesicles, simply through their enzymatic enrichment in ceramide. Addition of neutral sphingomyelinase (N-SMAse) in a cell-free system was sufficient in this case to trigger the inward vesiculation process similar to generation of ILV. ${ }^{104} \mathrm{It}$ is noteworthy that $\mathrm{N}$-SMAse involved in this form of vesiculation is different from the A-SMAse involved in the generation of cellular membrane-derived MP/MV. ${ }^{71}$

It is thought that in the case of MVB that are destined for exocytosis the ESCRT processing for lysosomal destruction is aborted, ${ }^{104}$ and the MVB are redirected to the plasma membrane, where they release their inner microvesicles (ILV; true $\mathrm{EXSM}^{106}$ ) into cellular surroundings. ${ }^{13,104}$ Thus the unique biogenesis of EXSM renders them fundamentally different from the MP/MV originating directly at the plasma membrane. ${ }^{13,82}$ Indeed, EXSM are much smaller in size ( $<50$ to $100 \mathrm{~nm})$ than MP/MV (100 to $1000 \mathrm{~nm}$ ), and they contain different types of molecular cargo. ${ }^{19,77}$ This includes a significant enrichment in heat shock proteins (HSP-70) and tetraspanins (CD63; Tspan8) ${ }^{77,107}$ but lower content of exposed PS. ${ }^{71}$ In some cases cells simultaneously produce several sizes (and types) of MV, ${ }^{82}$ including EXSM, each type endowed with different cargo and biological properties. ${ }^{108}$ In cancer, production of EXSM may be influenced by oncogenes and tumor suppressor genes. ${ }^{74,75,109}$ In particular, the p53 gene product appears to regulate biogenesis of EXSM by upregulating TSAP6 protein in irradiated cancer cells. ${ }^{75}$

It is presently unclear how oncogenic transformation, tumor microenvironment, therapeutic agents, interactions with other cells, and other influences affect various pathways of cellular vesiculation in cancer. Oncogenic signals trigger formation of MP/MV by human glioma cells, ${ }^{23}$ which are also known to produce ample amounts of EXSM. ${ }^{62,81}$ In vivo, these pathways likely intersect with regulatory responses to hypoxia, inflammation, and cytotoxicity, ${ }^{27}$ all of which may contribute to the generation of unique combinations of $\mathrm{EXSM}^{109}$ and membrane $\mathrm{MV},{ }^{23}$ and to changes in their content. Similarly, cell lineage definition, cancer type, cellular differentiation, and processes of epithelial to mesenchymal transition $(\mathrm{EMT})^{110}$ appear to influence patterns of cellular vesiculation, as does formation of the stem cell population $^{111}$ and the related intercellular interactions within the stem cell hierarchy. ${ }^{45}$

\section{BIOLOGICAL ROLES OF THE VESICULATION PROCESS}

There is no single or conclusive answer to the question why the mechanisms of MP/MV production have evolved in various organisms and what are their ultimate physiological roles. ${ }^{12,13,20,26}$ This question is even more complex in the context of cancer, where the analyses of vesiculation have largely been correlative, and evidence in vivo as to the causative, or rate-limiting roles of $\mathrm{MP} / \mathrm{MV}$ is relatively rare. ${ }^{22}$

It is not known whether hereditary defects in vesiculation, such as Scott's or Castaman's syndromes, ${ }^{30}$ affect cancer progression and by what mechanism. However, inferences as to the role of vesiculation in cancer can be made from correlative studies in clinical and preclinical settings, ${ }^{29,112}$ and from studies conducted in vitro. The latter suggest that production of $\mathrm{MP} / \mathrm{MV}$ could serve as a rapid and efficient mode of removal (shedding), relocation, or transfer between the cells of certain molecular components. Such a mechanism could bypass the barriers associated with the relative insolubility of molecules and their complexes (e.g., of transmembrane receptors ${ }^{23,113}$ ) or inefficient secretion of certain ligands (e.g., those lacking signal peptides ${ }^{31,71}$ ). Vesiculation could also circumvent the inefficiencies of the lysosomal degradation system, as was described in the case of transferrin removal from reticulocytes. ${ }^{19}$ It is possible that shedding of MP/MV containing oncogenic cargo (e.g., mutant EGFR) ${ }^{18}$ may also be triggered, as a form of primordial cellular defense from the signaling "overload" that may be associated with overexpression of these highly active proteins.

MP are also a part of the antigen presentation and immunomodulation apparatus. In this capacity their shedding could mediate interactions between cancer cells and the immune system, where MP could serve "defensive" purposes. For instance, rapid removal of the complement attack complexes from opsonized cells ${ }^{13}$ could potentially be activated in tumor cells, protecting them from complement-mediated lysis. Such cells could also use MV as a means to deploy various immunomodulating activities (e.g., cytokines or antigens), changing the 
patterns of host responses. ${ }^{36}$ In certain contexts, including oral, colorectal, and other cancers, MP/MV may also perform an "offensive" function, for instance, as carriers of Fas ligand. Contact with such MP/MV could induce apoptosis of innate and antigen-specific immune effector cells. $^{36,114-117}$

In certain instances MP may also serve the purpose of "nonconventional" release and gradient formation by cytokines, ${ }^{71}$ biological transmitters, ${ }^{12}$ membrane-anchored receptors, adhesion molecules, enzymes, and signaling proteins. ${ }^{12,13,23}$ This mode of release was implicated during formation of gradients of active morphogens involved in normal development. ${ }^{118}$ It is noteworthy that similar molecular entities, such as wingless $(\mathrm{Wnt})^{119}$ or hedgehog $(\mathrm{Hh}),{ }^{120}$ have also been implicated in cancer. ${ }^{45,121}$ Less clear is the role of mRNA and microRNA inclusion into various MP/ MV. Again, the removal and/or intercellular transfer of these molecular species are the most compelling explanations of their role as cargo of $\mathrm{MV} / \mathrm{MP} .^{12,77}$

\section{INTERCELLULAR EXCHANGE OF MOLECULAR INFORMATION VIA MICROVESICLES}

MV are known to transfer biologically active materials between cells. ${ }^{35}$ However, the scope of biological consequences unleashed by this process are highly context specific and still poorly understood. ${ }^{23,46,62,122}$ Most studies in this area revolve around such events as the activation of the coagulation system, inflammation, immune responses and neuronal communication, ${ }^{12,20,33,34,123,124}$ and some pathologies including cancer. ${ }^{12,18,34}$

The significance of MV-mediated intercellular communication is usually inferred from the nature of molecules found within or on the surfaces of these structures. ${ }^{53,58,125,126}$ The uniqueness of this communication stems from at least two properties, namely (1) the capacity to transfer multiple effectors at once, including molecules that are normally insoluble, ${ }^{62}$ and (2) the inclusion of molecules in the active and/or otherwise intact state. ${ }^{18}$ For instance, various soluble splice variants' cellular receptors, their fragments, and degradation products may be found in the intercellular space or blood but mainly in an inactive state and in the absence of their natural signaling partners and interactors. In contrast, many of the same entities (transmembrane receptors, membrane-bound ligands, signal peptide-deficient growth factors, cytoplasmatic and nuclear proteins, mRNA and microRNA) may exit cells as cargo of $\mathrm{MV} / \mathrm{MP}$, often intact and in their natural activation state (e.g., phosphorylated). ${ }^{12}$ Their entry into another cell, therefore, may cause functional changes unachievable in any other manner.

It has recently come to light that in cancer, the intercellular, MV-mediated transfer processes may en- compass cancer-specific molecules and activities, such as those associated with active oncoproteins, ${ }^{127}$ as well as intact oncogenic RNA species. ${ }^{62}$ However, other molecules of pathogenic significance could also be a part of this molecular exchange, whether emanating from cancer cells or their related host cell compartment. ${ }^{12}$ Indeed, the available evidence supports the possibility of microvesicular "sharing" of TF and certain oncogenic receptors between cancer cells and endothelium, ${ }^{22,128}$ a process that could clearly affect tumor angiogenesis. Similar transfers of transmembrane molecules could, at least in theory, include several other entities (e.g., VEGF receptors, Tie receptors, Notch receptors and their ligands, ephrins and Eph receptors, adhesion molecules, and integrins along with many others). It is intriguing to consider that vesiculation could in some instances extend the range, gradient, or change the signaling characteristics of the cell-associated (juxtacrine) ligand-receptor systems. Some intriguing clues to this effect have already begun to emerge from studies on the Notch system (Adrian Harris, personal communication).

Although direct studies in vivo on the microvesicular transfer are both difficult and scarce, several lines of more indirect evidence have recently emerged as to the possible biological significance of such a process. Thus microvesicular release/transfer has been implicated in the case of coagulation factors (e.g., $\mathrm{TF}^{46,128}$ ), chemokine receptors (CCR5), ${ }^{113}$ adhesion molecules, ${ }^{129}$ immunomodulators, ${ }^{36}$ cell surface antigens, ${ }^{125}$ intact RNA species, ${ }^{12,77}$ and cancer-associated proteins (oncoproteins). ${ }^{23,67,109}$ Similarly, the passage of carbonic anhydrase to lymphocytes by $\mathrm{MV} / \mathrm{MP}^{130}$ or transfer of phospholipids from red blood cells to their nucleated counterpart have recently been reported. ${ }^{131}$

Among these studies, a particularly instructive and, indeed, a seminal example was described by Mack et al. ${ }^{113}$ These investigators demonstrated that a chemokine receptor (CCR5) is released from epithelial cells as cargo of $\mathrm{MP}$, and those particles are subsequently taken up by mononuclear or endothelial cells. The resulting CCR5 transfer to these cells is highly consequential because it allows them to use CCR 5 as an entry portal for the human immunodeficiency virus 1 , thereby propagating the infection. ${ }^{113}$ It is tempting to speculate that similar MP-mediated uptake mechanisms may apply to other receptors and may also sensitize cells to other viruses, prions, or to stimulation with alternative ligands. Such events could also provoke autocrine/intracrine responses to ligands that the recipient cells may already produce. The latter is exemplified by the activation of the VEGF/VEGFR2 pathway in endothelial cells stimulated with EGFR-bearing MV. ${ }^{22}$

Perhaps one of the most intriguing effects of MV is their ability to transmit differentiation regulating signals and effectively trigger the reprogramming of target cells. A fascinating example of such an effect is 
described in the recent study by Ratajczak et al, who demonstrated the capacity of MV emanating from pluripotential embryonic stem (ES) cells to interact with hematopoietic progenitors, which are thereby induced to express genes related to pluripotentiality (Oct4, Nanog, Rex-1). In this case the MV recipient cells also acquired markers of early hematopoietic differentiation (Scl, HoxB4), along with biological and growth responses attributable, at least in part, to the uptake of the ES cell-related mRNA cargo. ${ }^{45}$ In another elegant study, hedgehog $(\mathrm{Hh})$ proteins were found to be emitted in the cargo of $\mathrm{MV}$ produced by stimulated $\mathrm{T}$ cells, and their uptake led to the reprogramming of K562 erythroleukemic cells, or primary CD34 + cells toward the megakaryocytic linage. ${ }^{121} \mathrm{MV}$ were also implicated in morphogenic and developmental events in nonmammalian systems in vivo, ${ }^{118}$ and there is no reason to exclude such interactions in higher organisms.

The emerging evidence suggests that emission of MV and EXSM may participate in formation of the growth-supporting niches for stem cells in various physiological or pathological settings. ${ }^{49,55,60,132}$ Such MV exchanges may occur between vascular, inflammatory, and transformed cells, and influence multicellular effects associated with cancer initiation, progression, angiogenesis, and metastasis. ${ }^{12,18,31}$ The potential of membrane MV and EXSM in this regard is underscored by several recent comprehensive studies on their molecular content (proteome, transcriptome, and profile of microRNA). Such profiling studies have been performed in several cell systems, including mast cells, ${ }^{77}$ fibroblasts, ${ }^{78}$ epithelial cells, ${ }^{133,134}$ endothelium, ${ }^{27,135}$ and different types of cancer cells. ${ }^{62,134,136-138}$ For instance, MV derived from human glioma cells were demonstrated to contain a wide spectrum of proteins, cytokines, chemokines, and $\sim 4700$ unique transcripts that were not detected (or differed in abundance) in the transcriptome of the corresponding tumor cells. ${ }^{62}$ Interestingly, this analysis was performed on tissue isolates, which normally contain different cellular subsets. Consequently, the heterogenous cellular sources could result in heterogenous composition of MV/MP and thereby increase the diversity of microvesicular mRNA, microRNA, and proteins, ${ }^{62}$ very much as would be expected to occur in vivo.

Although most of the MV/MP studies are performed in cell culture systems, there is a growing body of evidence supporting the occurrence of microvesicular transfer in vivo. ${ }^{23,139,140}$ For instance, MP/MV containing TF are readily detected in the blood of experimental animals and cancer patients, ${ }^{26,29,139}$ and EGFRvIII containing oncosomes has been detected in blood and in inoculates of cancer cells in mice. ${ }^{23}$ In such settings, MP/MV are thought to be short lived (up to 20 to 60 minutes in the circulation ${ }^{139,140}$ ), likely due to their rapid uptake by target cells or through other forms of bioelimination (possibly via interaction of their surface
PS with the phagocytic system). However, the biological consequences of MV uptake may be relatively long lasting (days). ${ }^{23}$ This combination of potent impact and short half-life may endow a microvesicular mode of signal delivery with unique characteristics.

The mechanisms of MV/MP uptake by various cells are a subject of ongoing studies. In some instances the evidence points to specific recognition mechanisms, for example, mediated by molecules expressed on the surfaces of MV/MP and those of recipient cells. For instance, the uptake of procoagulant MP by platelets may occur in a manner that depends on their expression of P-selectin, which recognizes the PSGL-1 on the membranes of MP. ${ }^{129}$ In other instances, MV may use their exposed PS to bind to the corresponding cellular PS receptors (PSRs). Such PSRs are often expressed by macrophages, and they participate in the phagocytic recognition of apoptotic cells, which also have a compromised lipid asymmetry and expose PS on their outer surfaces. Interestingly, PS-positive MP may bind to viable cells as well and "falsely" tag them for macrophage recognition. ${ }^{131}$ In contrast, MP may interact with PSRs on viable cells in a manner that does not necessarily provoke phagocytosis but instead leads to a merger between the interacting plasma membranes. PS moieties present on the surface of microvesicles can be blocked using annexin $\mathrm{V}$ or its derivatives (Diannexin), an effect that attenuates the MV uptake by target cells and prevents the exchange of their cargo. ${ }^{23,46}$ Although EXSM are often regarded as exposing relatively low levels of PS, PSRs have also been implicated in their cellular uptake. ${ }^{141}$ Several PSRs have recently been described, including Tim1, Tim4, stabilin 2, or BAI $1,{ }^{141,142}$ at least some of which may be involved in the cellular uptake of PS-positive MP in various settings. ${ }^{141}$ It has also been proposed that by interacting with Tim1/4 receptors on two adjacent cells, microvesicles could create intercellular bridges and thereby promote additional intercellular interactions. ${ }^{141}$ Interestingly, one of the PSRs (BAI1) is also known as a potent endogenous angiogenesis inhibitor. BAI1 was originally isolated from brain tissue and found to be regulated by the levels of p53. ${ }^{143}$ Whether the role of this receptor in angiogenesis is related to its interactions with PS-positive MP remains both highly intriguing and relatively unexplored. It is thought provoking that both cellular vesiculation ${ }^{23,74,75}$ and some of the mechanisms of MV/MP uptake (e.g., BAI1) could be controlled by oncogenic pathways. A corollary to this point could be that genes involved in malignant transformation could alter the level of intercellular communication via MV/MP.

It is not always clear what type of membrane fusion mechanisms are used by MP/MV interacting with surfaces of their target cells. For instance, subsets of membrane-derived MP endowed with low PS content ${ }^{122}$ or 
cellular EXSM may employ alternative modes of interactions with their recipients. In the case of some vesicles (e.g., synaptic vesicles), their contact with the plasma membrane may occur in a protein-assisted manner, which is thought to lead to direct interactions between juxtaposed lipid surfaces. ${ }^{144}$ Experiments involving differential fluorescent labeling of membrane lipids revealed changes in the emission wavelength upon MP uptake. ${ }^{46}$ This is indicative of the mixing process between MP-related and cell-associated membrane phospholipids. ${ }^{46}$ Similar conclusions can be drawn from the lengthy retention on the surfaces of target cells of MP-derived fluorescent dyes, catalytic activities (e.g., procoagulant TF activity), or transmembrane receptors (e.g., TF, EGFR; CCR5). Other mechanisms of MP/MV uptake have also been suggested, including intracellular penetration of intact vesicles. This is inferred from detection of such vesicles and their cargo within the cytoplasm of the acceptor/ target cell (e.g., using immunological or electron microscopy methods). 6,62 The consequences of these different modes of MV/MP-cellular contact are poorly understood.

\section{MICROPARTICLES AS REGULATORS OF THE COAGULATION SYSTEM IN CANCER}

Historically, the prominent biological role of MP/MV was first detected, ${ }^{32-34}$ and subsequently has been long studied, in the context of the coagulation system..$^{26,30,122}$ This area has been covered extensively by several excellent recent reviews, ${ }^{25,26,30,122,145-147}$ and therefore we concentrate only on selected key questions. In this regard, the long-standing puzzle is related to the exact pathomechanism of the systemic coagulopathy in patients with localized and especially advanced cancers who also may exhibit high levels of circulating MP/MV. ${ }^{148-151}$

In spite of its long history, ${ }^{152}$ the linkage between cancer and abnormal coagulation is still surrounded by several unanswered questions, including (1) Are the mechanisms of cancer-related thrombosis cancer specific and to what extent? (2) Is this specificity (if any) linked to properties of cancer cells and in what ways? (3) What mediates systemic changes associated with events (tumors) that may occur locally? (4) What are the implications of cancer-dependent molecular changes for thrombosis-related patient survival? and (5) What are the implications of hemostatic perturbations for anticancer therapy? Inclusion of MP in studies related to these questions has recently led to several useful clues.

Cancer patients exhibit heightened levels of circulating procoagulant MP that correlate with the risk of thrombosis. ${ }^{26,29,48,112,146,153}$ In some instances, such procoagulant MP may emanate from platelets or inflammatory cells, or be produced by fusion between vesicles of different origin. ${ }^{29}$ However, there is an increasing appreciation for the notion that cancer cells themselves may be a source of procoagulant MP. This is suggested by the nature of the procoagulant activity associated with such MP, which appears to reside in their content of PS, TF, and MUC1. ${ }^{26,29}$ The latter two types of cargo are often upregulated by cancer cells. $^{29,149,151}$ Moreover, the levels of circulating MP are often diminished after the surgical tumor removal. ${ }^{146}$ In experimental studies, procoagulant MP were found to home to sites of ongoing thrombosis. More specifically, in mice harboring tumors engineered to emit fluorescent MP (tagged with enhanced green fluorescent protein), the experimental bleeding times were generally shortened, and the fluorescent signal associated with procoagulant (tumor-derived) MP accumulated in emerging clots. ${ }^{139}$ This suggests that cancer cells may be a major source of procoagulant TF-containing MP circulating in blood and that such MP may exert systemic vascular effects, ${ }^{139}$ at least in part as a function of malignant transformation. ${ }^{74,154}$

Indeed, oncogenic transformation emerges as a major trigger of both cancer coagulopathy and cellular vesiculation. ${ }^{18,155}$ Mutant K-ras, EGFR, and $\mathrm{p} 53^{23,74}$ upregulate TF expression by cancer cells and have been shown to directly trigger the emission of $\mathrm{TF}$-containing MP. ${ }^{74,110}$ Certain other cancer-related processes such as formation of the stem cell (CSC) compartment and EMT may also lead to both TF overexpression and the release of TF-bearing MP. ${ }^{110,156}$ Interestingly, cancer treatment with oncogene-directed (targeted) agents appears to diminish the extent of thrombosis in patients. This has been reported for acute promyelocytic leukemia in the course of treatment with all-trans retinoid acid, which inhibits the activity of the RAR $\alpha$ - PML oncogene. ${ }^{157}$ Similarly, in gastrointestinal stromal tumors (GIST), treatment with imatinib mesylate (Gleevec) was found to reduce coagulopathy. ${ }^{158}$ The latter finding suggests that the activity of the c-Kit oncogene, which drives pathogenesis of GIST, may be involved in the deregulation of coagulation effectors in this disease, conceivably including TF and/or release of procoagulant MP.

MP are increasingly well established as carriers of procoagulant activity throughout the systemic circulation. ${ }^{159}$ As mentioned earlier, the levels of circulating procoagulant MP correlate with the risk of cancer-related thrombosis. ${ }^{25,26,29,30,46,112,160}$ In contrast, deficient vesiculation correlates with bleeding propensities in patients with Scott's syndrome. ${ }^{35}$ It is not known whether such patients develop cancer and what the biological and procoagulant characteristics of the disease in such settings would be. ${ }^{18}$ Further suggestion that MP may be central to the coagulation process come from experiments demonstrating the transfer of coagulation regulators between cells, a process found to contribute to the assembly of active procoagulant complexes on cellular surfaces. $^{12,26,30,122}$ Effects of this nature may result in the amplification of TF activity, ${ }^{25,26,30,34}$ and MP-mediated 
accumulation of this receptor has been documented for endothelial cells, ${ }^{47,128}$ platelets, ${ }^{46}$ and with growing thrombi. ${ }^{139}$

The role of MP in cancer coagulopathy deserves a few additional comments. Although cancer cells may make a direct contribution to the pool of circulating procoagulant MP (as previously outlined), their influence may also be indirect, for example, mediated through release of soluble mediators that mobilize and activate other cells (platelets, phagocytes, endothelial cells, or fibroblasts). ${ }^{128,161,162}$ Given the emerging role of MP in driving cancer-related coagulopathy, therapeutic strategies targeting MP may represent an interesting and relatively unexplored option in this particular setting. In this regard, certain novel antithrombotic agents directed at PS, notably Diannexin, ${ }^{163}$ could potentially be of interest (Meehan et al, unpublished data, ${ }^{22}$ ). Furthermore, although the most attention has been focused on cancer-related procoagulant MP, these vesicles could also harbor or induce anticoagulant and fibrinolytic proteins, including tissue factor pathway inhibitor (TFPI) ${ }^{26}$ activated protein $\mathrm{C}$ and its receptor, thrombomodulin, ${ }^{122}$ or urokinase. ${ }^{164}$ Although procoagulant (and anticoagulant) cancer-related MP have a potential to modulate not only coagulopathy but also tumor angiogenesis, progression, and metastasis, few studies have examined these latter issues in detail.

\section{THE INVOLVEMENT OF MICROPARTICLES IN TUMOR ANGIOGENESIS}

Membrane vesicles and EXSM have been implicated in various aspects of vascular regulation, including the tumor-vascular interface. ${ }^{22,53-56,92,165-170}$ Indeed, the involvement of the vascular system in malignancy is well established and multifaceted. ${ }^{171}$ This entails not only the supply of oxygen, growth factors, metabolites, and hormones but also regulatory (angiocrine) functions and the role of a conduit for metastasis. ${ }^{172}$ The extent to which these processes are clinically relevant is reflected by the recent approval of at least four antiangiogenic agents (many more remaining in the pipeline), as the mainstay or as adjunctive anticancer therapy. ${ }^{172,173}$ This list currently includes bevacizumab, sunitinib, sorafenib, and pazopanib, all of which are directed, at least in part, against VEGF and its endothelial receptors (VEGFR1$3)$. Both the angiogenesis process itself ${ }^{74}$ and antiangiogenic therapy ${ }^{175}$ are also associated with perturbations within the coagulation system, which may involve processes mediated by procoagulant MP described earlier. There are, however, emerging suggestions as to coagulation-independent activities of various cellular vesicles (including membrane MV and EXSM) emanating from cancer cells and stroma in tumor angiogenesis. ${ }^{18,53}$

Tumor neovascularization is triggered and maintained by a complex network of interactions between various subsets of cells. ${ }^{176,177}$ This includes heterogenous tumor cell subpopulations (cancer stem cells/tumor initiating cells and their progeny), stromal fibroblasts, resident endothelial cells, endothelial progenitor cells, inflammatory cells, and their bone marrow-derived precursors and platelets, all of which contribute different activities to the emerging tumor microcirculation. ${ }^{176,178,179}$ The onset of this process can be traced to the combined and/or sequential change in expression of angiogenesis-regulating genes (stimulators, inhibitors, and modulators), which is triggered by activated oncogenic pathways, hypoxia, and inflammatory mediators. ${ }^{180}$ These events are traditionally described in (uni)molecular terms. Thus growth factors such as VEGF, angiopoietins (Ang1/2), ephrins, and delta-like 4 (D114) act on their respective receptors (VEGFR1-3, Tie2, Eph, Notch), ${ }^{172,177}$ and in concert with adhesion molecules, integrins, and their extracellular matrix they are thought to orchestrate the neovascular expansion. ${ }^{177-180}$ Moreover, these interactions activate several pathways of blood vessel formation, ${ }^{176,177,181,182}$ in which endothelial cells, pericytes, bone marrow derived (regulatory) cells, ${ }^{179}$ endothelial progenitor cells (EPCs), and platelets ${ }^{183-185}$ play relatively well-defined and complementary roles. ${ }^{26,177,178}$ In this regard, one of the best described is the process of vascular sprouting. In this case the activated endothelial cells of the vessel wall (phalanx cells) deploy cohorts of endothelial cells (sprouts). Sprouts are composed of columns of growing and migrating endothelial cells (stalk cells) moving in the direction defined by the angiogenic gradient (e.g., concentration of VEGF), which is detected by specialized leading cells (tip cells). Tip cells are equipped with high levels of VEGF and PDGF receptors, as well as other characteristics such as high levels of the Notch ligand, D114. ${ }^{179,186}$ Angiogenesis is modulated by the influences of other regulatory systems. For instance, the coagulation system impacts the angiogenic process through release of regulators from platelets but also through effects afforded by the fibrin clot and the signaling input of $\mathrm{TF}$, factor $\mathrm{Xa}$, thrombin, and protease-activated receptors. ${ }^{74,183,187-190}$ Other pathways may also modulate the outcome of vascular growth, and the details of the related events have been summarized elsewhere. ${ }^{177,179}$ Operationally then, tumor neovascularization entails the expansion of the preexisting microvascular network (angiogenesis), recruitment of EPCs to the sites of blood vessel formation (vasculogenesis), remodeling and regression of the emerging structures, ${ }^{177}$ as well as cooption and invasion of normal vessels by cancer cells. ${ }^{176,178,191}$

There is presently no conclusive evidence that angiogenesis cannot proceed in the absence of vesiculation. This can be inferred from the disparity between the dramatic phenotypic consequences (lethality) that accompany deficiencies in expression of the so-called 
professional angiogenic pathways (e.g., VEGF/ VEGFR) and much milder consequences of disrupted cellular vesiculation. The latter is observed in patients with Scott's syndrome, where vascular development is essentially spared. ${ }^{35}$ However, under more specific circumstances, cellular vesiculation (e.g., occurring in endothelial cells, cancer cells, and platelets) may play an important role in the stimulation and modulation of tumor angiogenesis.

Indeed, as mentioned earlier, tumor- and plateletderived $\mathrm{MV}$ are a rich source of angiogenic growth factors (VEGF, FGF), ${ }^{31,58}$ proinflammatory cytokines $\left(\text { IL1 }^{71} \text {, proteases (MT1-MMP) }\right)^{54}$ and their inducers (CD147/EMMPRIN), ${ }^{192}$ all of which could contribute to the proangiogenic intratumoral milieu, either directly or indirectly. ${ }^{12,31}$ This could occur through several processes, including (1) intercellular transfer or proangiogenic cargo, (2) pericellular release of proangiogenic content of MV, or by (3) induction of proangiogenic gene expression upon contact between vascular cells and MV. 22,26,53,54,193,194

Thus proangiogenic effects could be induced though the endothelial uptake of molecular cargo containing activating molecules. For example, endothelial progenitor cells emit MV containing mRNA, which can be transferred to resident endothelial cells causing their angiogenic activation. ${ }^{55}$ Endothelial cells can also respond to transfer of mRNA from tumor cells ${ }^{62}$ or to the uptake of MV containing active EGFR oncoproteins. ${ }^{22}$ In the latter case, endothelial cells become positive for EGFR, both in vivo and in vitro, and they initiate production of endogenous/autocrine angiogenic activity (VEGF). This leads to activation of VEGFR2, an effect resistant to addition of VEGF-neutralizing antibodies (Avastin) but obliterated by intracellularly acting VEGFR2 kinase inhibitors (SU5416). In this setting, the blockade of MV-associated EGFR using a pan-Erb inhibitor (CI-1033) and blockade of PS (using Diannexin) abrogate the proangiogenic effects. Notably, Diannexin treatment in vivo produces inhibition of EGFR-driven tumor growth and leads to a reduction in microvascular density (MVD) ${ }^{22}$

It is of interest that a vesicular transfer of EGFR into cells that normally express this receptor at low levels may sensitize these cells to EGFR ligands (e.g., EGF). In the case of endothelial cells, this may result in an acquisition of proangiogenic activity by ligands that may normally stimulate this process weakly or not at all. Similarly, endothelial cells exposed to MV containing $\mathrm{TF}^{128}$ (and possibly PARs) could become more susceptible to stimulation by the signaling effectors of the coagulation system, including factor VIIa and thrombin, both already implicated in angiogenesis regulation. ${ }^{161,195}$ Indeed, this could be one way by which an increase in levels of procoagulant MV/MP circulating in the blood of cancer patients could promote tumor angiogenesis and progression. Although these possibilities are intriguing, the extent to which reprogramming of endothelial cells may occur via MV-mediated transfer of "heterotypic" receptors (Fig. 1) remains to be investigated in more detail.

Intercellular transfer of MV may also operate between cancer cells, leading to amplification of their angiogenic phenotype. In this regard, it has been proposed that in spite of their proangiogenic effects, oncogenic mutations in individual cells may not be able to trigger an overt onset of vascular growth. This is because such cancer cells would be surrounded with non/antiangiogenic stromal cells or poorly angiogenic masses of indolent cancer cells, whose inhibitory effects may be difficult to overcome. ${ }^{127}$ However, angiogenic switch in cancer would occur more readily if a coordinated proangiogenic change could be induced in multiple cells. ${ }^{127}$ One way of achieving such an effect could be through the intercellular exchange of $\mathrm{MV} .^{23}$ Indeed, glioblastoma cells expressing mutant EGFRvIII oncogene emit $\mathrm{MV}$, which can be taken up by indolent tumor cells, followed by this receptor activating (ectopically) its downstream targets, such as VEGF. ${ }^{23}$ In this manner a relatively smaller number of cells harboring the mutant EGFRvIII gene may affect a larger population of cells, in which the microvesicular uptake of the respective oncoprotein may induce a "collective" angiogenic phenotype. ${ }^{18}$ Again, direct evidence for this scenario is to be established, but it is striking that expression of EGFRvIII in human glioblastoma occurs almost always in a minority of tumor cells while affecting the disease as a whole. ${ }^{196}$

As mentioned earlier, vesicles emanating from tumor and stromal cells may serve as an alternative mechanism for the release of angiogenic factors, cytokines, or proangiogenic enzymes that are cell associated, lack signal peptides, or are unstable in the extracellular environment. For instance, in spite of the inefficient standard secretion mechanisms, IL-1ßis released from ATP-stimulated glial cells via membrane MV. ${ }^{71} \mathrm{Sim}-$ ilarly puzzling is the long-standing paradox of the high paracrine and proangiogenic activity of fibroblast growth factor (FGF)2, which lacks the signal peptide. Again, this could be explained by evidence that this growth factor can be released in a form of MV. ${ }^{197,198}$ In spite of the efficient molecular release of VEGF, this factor is also found in the cargo of tumor-related MV and is liberated upon disruption of the MV membranes. ${ }^{58} \mathrm{It}$ is possible that this form of VEGF release protects this and other factors from proteolytic degradation. As mentioned earlier, MV may be recognized by target cells (whether transformed, inflammatory, or endothelial) via a mechanism involving PS and PSRs. ${ }^{141}$ One such PRS, known as BAI1, is a known inhibitor of angiogenesis, which raises questions as to the role of microvesicular uptake in angiogenesis regulation. ${ }^{12,22,31}$ 


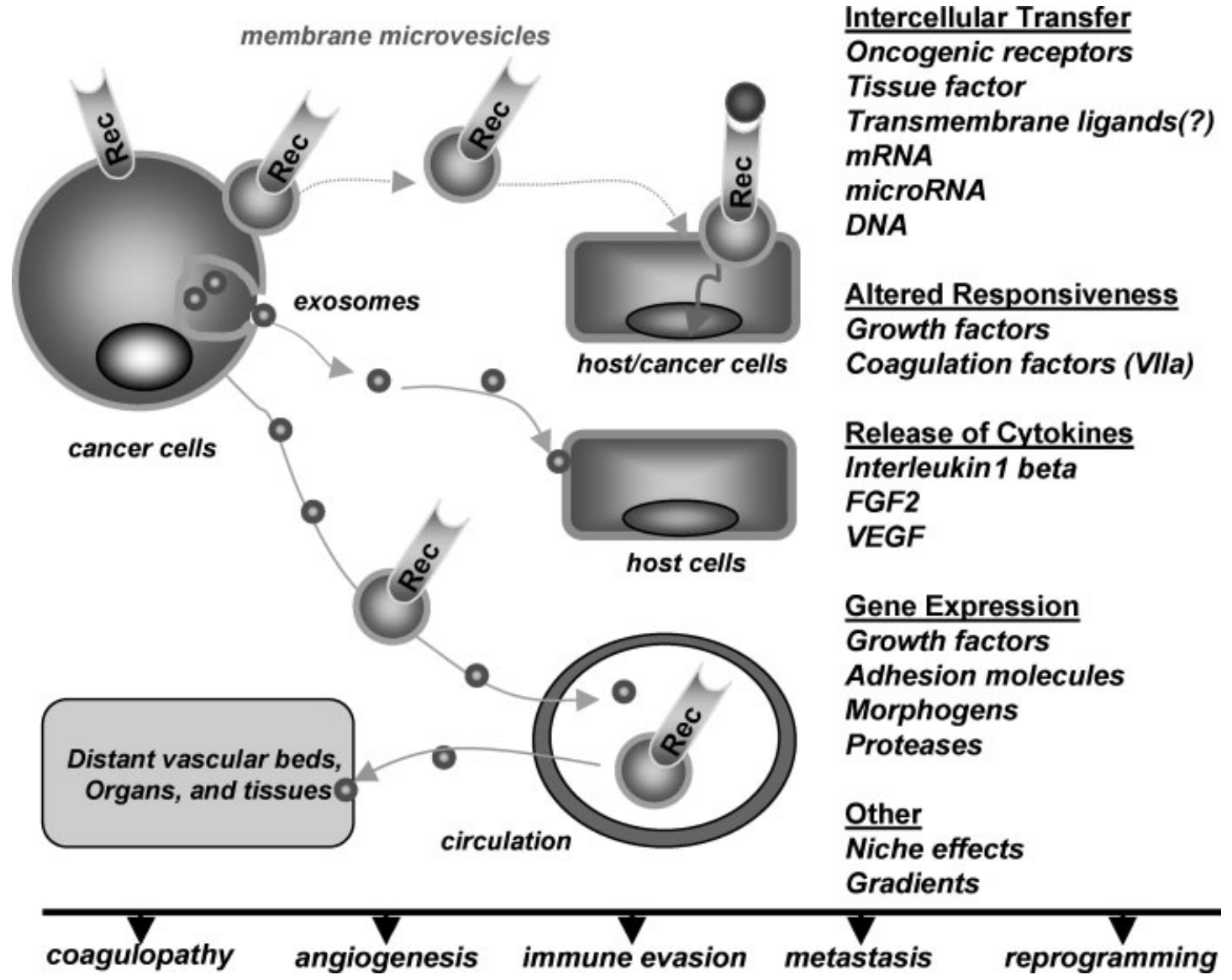

Figure 1 Microparticle-mediated biological responses in cancer. Both plasma membrane-derived microvesicles and intracellularly formed microvesicles (exosomes) are emitted by cancer cells and stroma and contribute to integrated cellular responses. The nature of this influence may involve transfer of microparticle cargo or stimulatory effects on endogenous production of various effectors. Oncoproteins and regulatory receptors (e.g., epidermal growth factor receptor) stimulate vesiculation and become a cargo of cancer-related microvesicles, which transfer them to other cells. Processes affected by microparticle exchange include coagulopathy, angiogenesis, metastasis, and many others. FGF2, fibroblast growth factor receptor 2; VEGF, vascular endothelial growth factor.

The induction of angiogenic activities in various cells (e.g., cancer cells or endothelium) may occur by the novo gene expression or mRNA transfer upon contact with MV and EXSM. Thus Janowska-Wieczorek et al reported a multifactorial change in the angiogenic phenotype of human lung cancer cells in vitro upon their exposure to PMP. ${ }^{54}$ In this instance, the target cells were found to take up the platelet antigen CD41 while at the same time exhibiting increased MAPK phosphorylation and expression of transcripts for MMP9, VEGF, IL8, and hepatocyte growth factor. ${ }^{54}$ Although the specific mechanism of this induction is presently unclear, another study explored the impact of EXSM bearing Tspan8/D6.1A/CO-029 tetraspanin on the activation of endothelial cells during tumor-driven angiogenesis. ${ }^{44,53}$ This proangiogenic effect directly depended on the Tspa8 tetraspanin, as indicated by experiments with specific neutralizing antibodies. The proangiogenic effects of these EXSM resulted in VEGR-dependent and independent deregulation of several genes, including chemokines (CXCL5, MIF), their receptors (CCR1), and VEGFR2. ${ }^{44}$ Microvesicles could also stimulate angiogenesis through a mechanism dependent on their lipid membranes $(\mathrm{SM})^{166}$ and through other mechanisms leading to deregulation of cytokines in endothelial cells. ${ }^{57}$ Overall, these observations raise the possibility that MV/MP-directed agents could have a role in antiangiogenic therapy. ${ }^{18}$

\section{THE ROLE OF MICROPARTICLES IN CANCER PROGRESSION AND METASTASIS}

As mentioned earlier, MV/MP production can be triggered by oncogenic receptors (e.g., EGFRvIII), which subsequently become incorporated into the MV cargo and exit the cell of origin. ${ }^{23}$ In this form, oncogenic EGFR and EGFRvIII were shown to be taken up by indolent cancer cells and normal cells. ${ }^{22,23}$ Such horizontal transfer of the MV content into various "acceptor" 
cells profoundly alters their properties, beyond the previously mentioned stimulation of angiogenesis. ${ }^{22} \mathrm{In}$ particular, microvesicular transfer of the active EGFRvIII oncogene from aggressive glioma cells to their indolent counterparts stimulated activation of MAPK and AKT pathways in these cells and altered their expression of genes regulating cell survival (BclxL) and proliferation (p27). This treatment also stimulated formation of three-dimensional colonies in semisolid medium (a hallmark of malignant transformation). ${ }^{23}$ Importantly, the treatment of MV containing oncogenic EGFRvIII with the irreversible pan-Erb kinase inhibitor diminished these effects, as did cloaking their PS residues with annexin $\mathrm{V}^{23}$ or Diannexin. ${ }^{22}$ Similarly, microvesicles collected from fresh isolates of human glioblastoma were found to stimulate proliferation of the U87 malignant glioma cells, and a similar material was also shown to contain mRNA encoding the mutant EGFR (EGFRvIII). ${ }^{62}$ EGFRvIII and EGFR were also found in tumor cell-derived EXSM. ${ }^{99,109}$

Several studies reported the impact of MV/MP on metastasis. ${ }^{28,54,60,61}$ Thus PMV/MP contribute to the metastatic phenotype of cancer cells. ${ }^{54,193}$ Tumor cells themselves may emit PS-containing MV that facilitated experimental dissemination of melanoma cells in mice. ${ }^{61}$ Exosomes were found to cooperate with CD44v6 in conditioning premetastatic niches for colonization by pancreatic cancer cells. ${ }^{60}$ Prometastatic proteins are released as a cargo of EXSM produced by epithelial cancer cells under hypoxia, along with alix and tertraspanins (CD9 and CD88). ${ }^{73}$ Increased production of TF-containing MP/MV correlates with induction of the proinvasive phenotype (EMT) in EGFRdriven cancer cells. ${ }^{110}$ In the course of human prostate cancer progression toward metastatic disease, the loss of DRF3 gene expression correlates with an increased vesiculation. ${ }^{28}$ These and other studies that have been reviewed recently ${ }^{12,26}$ point to the systemic, proinvasive, and vascular effects of $\mathrm{MP} / \mathrm{MV}$, all of which may play a role at various stages of tumor dissemination. Although these results are intriguing, the functional requirement for vesiculation has not been conclusively established in the course of metastatic disease in clinical settings. Nonetheless, it is of interest whether agents blocking $\mathrm{MP} / \mathrm{MV}$ production, uptake, or activity could be effective in treating disseminated cancer, either in an adjuvant setting or in the course of overt metastatic disease.

\section{ANTITHETICAL EFFECTS OF MICROPARTICLES AND EXOSOMES IN CANCER}

Although MP are often discussed as carriers of stimulating, or pathogenetic influences (e.g., in cancer progression, angiogenesis, and coagulopathy), it is possible that under certain circumstances they may also exert the opposite (inhibitory, cancer-suppressive) functions. For instance, it is of interest that EXSM contain a rich repertoire of micro RNA (miRs), ${ }^{77,199}$ including in the context of glioblastoma ${ }^{62}$ and possibly in other tumors. Indeed, miRs may exert either oncogenic or tumorsuppressive influences, depending on the nature of genes whose expression they regulate. ${ }^{199,200}$ Therefore, the action (transfer) of EXSM containing various miR species on cancer cells may be either stimulatory ${ }^{201}$ or inhibitory. The latter may apply to EXSM emanating from normal cells. Similarly, normal cells (stromal fibroblasts, inflammatory cells) may emit MP that contain growth-suppressing and anti-inflammatory proteins, for example, transforming growth factor (TGF) $\beta 1,{ }^{202}$ products of tumor suppressor genes (e.g., maspin), ${ }^{75,203}$ phosphatases, ${ }^{204,205}$ immunomodulators, ${ }^{90}$ and entities endowed with antiproteolytic (e.g., TIMP1), ${ }^{206}$ anticoagulant (e.g., EPCR or TFPI), ${ }^{26,122,207}$ or antiangiogenic activities (e.g., platelet factor 4) ${ }^{75,208}$ It should be mentioned, however, that with the emergence of the activated stroma ${ }^{209}$ and the related proangiogenic field effects orchestrated by cancer cells, ${ }^{210}$ the impact of normal cells may evolve and become tumor promoting over time. Similarly, the profiles of MP/MV and EXSM could evolve accordingly. Like the many other questions surrounding MP/MV biology, these possibilities require further studies.

\section{CIRCULATING MICROVESICLES AS BIOMARKERS IN MALIGNANCY}

MP released into blood, urine, and body fluids offers a unique opportunity to access, noninvasively, the biological information directly related (pathognomonic) to cancer and stromal cells. ${ }^{23}$ In addition, during surgical tumor tissue collection, or at biopsy, the regional differences in tumor cell properties may lead to sampling errors. ${ }^{211}$ In contrast, circulating MV/MP are readily accessible and could be subjected to a molecular analysis of varying depth and focus. In this regard, xenotransplants of human glioma shed MV containing oncogenic EGFRvIII, which can be readily detected in the circulating blood of tumor-bearing mice. ${ }^{23}$ EGFRvIII protein and $\mathrm{mRNA}^{62}$ could also be retrieved from MV/MP, or EXSM circulating in the blood of patients with malignant glioma. ${ }^{62,81}$ Similarly, the HER-2 oncoprotein could be detected in MV/MP isolated from culture media incubated with breast cancer cells. ${ }^{67}$

Indeed, the MV/MP-based technology could potentially yield useful prognostic and predictive insights. In this regard, selective or multiplexed assessment of oncogenic targets present in the cargo of blood-borne MV/MP, their status, splicing, posttranslational processing, and/or phosphorylation could be incorporated into protocols designed to monitor the effects of antitumor (Herceptin, Tarceva, Erbitux) and antiangiogenic 
(Avastin, Sutent, Nexavar) therapies. ${ }^{23,62,67}$ This could also potentially include testing for oncogenic mutations, ${ }^{62}$ as well as mutations that may confer sensitivity or resistance to pharmacological inhibitors. ${ }^{212}$

\section{CONCLUSIONS}

Studies on tumor-related membrane MV and EXSM have recently entered a phase of rapid progress. ${ }^{12,23,62,125}$ Cellular vesicles represent a fascinating and potentially useful reservoir (sanctuary) of biological information as to cancer-related processes such as oncogenic transformation, risk of thrombosis, angiogenesis, and other aspects. Their functional role still needs to be understood more fully, but the usefulness of various MP as disease biomarkers deserves immediate and extensive exploration.

\section{ACKNOWLEDGMENTS}

This work was supported by a grant from the Canadian Cancer Society Research Institute (CCSRI) to J.R., who is a holder of the Jack Cole Chair in Pediatric Oncology at McGill University. I am indebted to my colleagues and family for their continuous patience and care, especially Anna and Danuta Rak.

\section{REFERENCES}

1. Citri A, Yarden Y. EGF-ERBB signalling: towards the systems level. Nat Rev Mol Cell Biol 2006;7(7):505-516

2. Blume-Jensen $P$, Hunter T. Oncogenic kinase signalling. Nature 2001;411(6835):355-365

3. Pawson T. Protein modules and signalling networks. Nature 1995;373(6515):573-580

4. Houghton AM, Rzymkiewicz DM, Ji H, et al. Neutrophil elastase-mediated degradation of IRS-1 accelerates lung tumor growth. Nat Med 2010;16(2):219-223

5. Gillette JM, Larochelle A, Dunbar CE, LippincottSchwartz J. Intercellular transfer to signalling endosomes regulates an ex vivo bone marrow niche. Nat Cell Biol 2009; 11(3):303-311

6. Aharon A, Brenner B. The role of breast cancer cells microparticles in thrombogenicity following chemotherapy [abstract]. Thromb Res 2010;125:S179

7. Małecki J, Wiedłocha A, Wesche J, Olsnes S. Vesicle transmembrane potential is required for translocation to the cytosol of externally added FGF-1. EMBO J 2002;21(17): 4480-4490

8. Hunter T. Protein kinases and phosphatases: the yin and yang of protein phosphorylation and signaling. Cell 1995;80(2): 225-236

9. Heppner GH. Tumor cell societies. J Natl Cancer Inst 1989;81(9):648-649

10. Liotta LA, Kohn EC. The microenvironment of the tumour-host interface. Nature 2001;411(6835):375-379

11. Rak J. Is cancer stem cell a cell, or a multicellular unit capable of inducing angiogenesis? Med Hypotheses 2006;66(3): 601-604
12. Ratajczak J, Wysoczynski M, Hayek F, JanowskaWieczorek A, Ratajczak MZ. Membrane-derived microvesicles: important and underappreciated mediators of cell-to-cell communication. Leukemia 2006;20(9):14871495

13. Pilzer D, Gasser O, Moskovich O, Schifferli JA, Fishelson Z. Emission of membrane vesicles: roles in complement resistance, immunity and cancer. Springer Semin Immunopathol 2005;27(3):375-387

14. Davis DM, Sowinski S. Membrane nanotubes: dynamic long-distance connections between animal cells. Nat Rev Mol Cell Biol 2008;9(6):431-436

15. Sherer NM, Mothes W. Cytonemes and tunneling nanotubules in cell-cell communication and viral pathogenesis. Trends Cell Biol 2008;18(9):414-420

16. Ahmed KA, Xiang J. Mechanisms of cellular communication through intercellular protein transfer. J Cell Mol Med 2010;(January):11-[Epub ahead of print]

17. Caumartin J, Lemaoult J, Carosella ED. Intercellular exchanges of membrane patches (trogocytosis) highlight the next level of immune plasticity. Transpl Immunol 2006;17(1): 20-22

18. Al-Nedawi K, Meehan B, Rak J. Microvesicles: messengers and mediators of tumor progression. Cell Cycle 2009;8(13): 2014-2018

19. Johnstone RM. Exosomes biological significance: a concise review. Blood Cells Mol Dis 2006;36(2):315-321

20. Cocucci E, Racchetti G, Meldolesi J. Shedding microvesicles: artefacts no more. Trends Cell Biol 2009;19(2):43-51

21. Takamori S, Holt M, Stenius K, et al. Molecular anatomy of a trafficking organelle. Cell 2006;127(4):831-846

22. Al-Nedawi K, Meehan B, Kerbel RS, Allison AC, Rak J. Endothelial expression of autocrine VEGF upon the uptake of tumor-derived microvesicles containing oncogenic EGFR. Proc Natl Acad Sci U S A 2009;106(10): 3794-3799

23. Al-Nedawi K, Meehan B, Micallef J, et al. Intercellular transfer of the oncogenic receptor EGFRvIII by microvesicles derived from tumour cells. Nat Cell Biol 2008;10(5):619624

24. Yu JL, Rak JW. Shedding of tissue factor (TF)-containing microparticles rather than alternatively spliced $\mathrm{TF}$ is the main source of TF activity released from human cancer cells. J Thromb Haemost 2004;2(11):2065-2067

25. Zwicker JI, Furie BC, Furie B. Cancer-associated thrombosis. Crit Rev Oncol Hematol 2007;62(2):126-136

26. Aharon A, Brenner B. Microparticles, thrombosis and cancer. Best Pract Res Clin Haematol 2009;22(1):61-69

27. Diamant M, Tushuizen ME, Sturk A, Nieuwland R. Cellular microparticles: new players in the field of vascular disease?. Eur J Clin Invest 2004;34(6):392-401

28. Di Vizio D, Kim J, Hager MH, et al. Oncosome formation in prostate cancer: association with a region of frequent chromosomal deletion in metastatic disease. Cancer Res 2009;69(13):5601-5609

29. Tesselaar ME, Romijn FP, Van Der Linden IK, Prins FA, Bertina RM, Osanto S. Microparticle-associated tissue factor activity: a link between cancer and thrombosis?. J Thromb Haemost 2007;5(3):520-527

30. Burnier L, Fontana P, Kwak BR, Angelillo-Scherrer A. Cell-derived microparticles in haemostasis and vascular medicine. Thromb Haemost 2009;101(3):439-451 
31. Dolo V, D’Ascenzo S, Giusti I, Millimaggi D, Taraboletti G, Pavan A. Shedding of membrane vesicles by tumor and endothelial cells. Ital J Anat Embryol 2005;110(2, Suppl 1): 127-133

32. Chargaff E, West R. The biological significance of the thromboplastic protein of blood. J Biol Chem 1946;166(1): 189-197

33. Wolf $\mathrm{P}$. The nature and significance of platelet products in human plasma. Br J Haematol 1967;13(3):269-288

34. Dvorak HF, Quay SC, Orenstein NS, et al. Tumor shedding and coagulation. Science 1981;212(4497):923-924

35. Piccin A, Murphy WG, Smith OP. Circulating microparticles: pathophysiology and clinical implications. Blood Rev 2007;21(3):157-171

36. Valenti R, Huber V, Iero M, Filipazzi P, Parmiani G, Rivoltini L. Tumor-released microvesicles as vehicles of immunosuppression. Cancer Res 2007;67(7):2912-2915

37. Mayordomo JI, Zorina T, Storkus WJ, et al. Bone marrowderived dendritic cells pulsed with synthetic tumour peptides elicit protective and therapeutic antitumour immunity. Nat Med 1995;1(12):1297-1302

38. Williams RL, Urbé S. The emerging shape of the ESCRT machinery. Nat Rev Mol Cell Biol 2007;8(5):355-368

39. Simons M, Raposo G. Exosomes-vesicular carriers for intercellular communication. Curr Opin Cell Biol 2009; 21(4):575-581

40. Février B, Raposo G. Exosomes: endosomal-derived vesicles shipping extracellular messages. Curr Opin Cell Biol 2004; 16(4):415-421

41. Houseley J, LaCava J, Tollervey D. RNA-quality control by the exosome. Nat Rev Mol Cell Biol 2006;7(7):529-539

42. Enjeti AK, Lincz LF, Seldon M. Microparticles in health and disease. Semin Thromb Hemost 2008;34(7):683-691

43. Lynch SF, Ludlam CA. Plasma microparticles and vascular disorders. Br J Haematol 2007;137(1):36-48

44. Nazarenko I, Rana S, Baumann A, et al. Cell surface tetraspanin Tspan8 contributes to molecular pathways of exosome-induced endothelial cell activation. Cancer Res 2010;70(4):1668-1678

45. Ratajczak J, Miekus K, Kucia M, et al. Embryonic stem cellderived microvesicles reprogram hematopoietic progenitors: evidence for horizontal transfer of mRNA and protein delivery. Leukemia 2006;20(5):847-856

46. Del Conde I, Shrimpton CN, Thiagarajan P, López JA. Tissue-factor-bearing microvesicles arise from lipid rafts and fuse with activated platelets to initiate coagulation. Blood 2005;106(5):1604-1611

47. Aharon A, Tamari T, Brenner B. Monocyte-derived microparticles and exosomes induce procoagulant and apoptotic effects on endothelial cells. Thromb Haemost 2008;100(5):878-885

48. Tilley RE, Holscher T, Belani R, Nieva J, Mackman N. Tissue factor activity is increased in a combined platelet and microparticle sample from cancer patients. Thromb Res 2008;122(5):604-609

49. Castellana D, Zobairi F, Martinez MC, et al. Membrane microvesicles as actors in the establishment of a favorable prostatic tumoral niche: a role for activated fibroblasts and CX3CL1-CX3CR1 axis. Cancer Res 2009;69(3):785-793

50. Doeuvre L, Angles-Cano E. Cell-derived microparticles unveil their fibrinolytic and proteolytic function [in French]. Med Sci (Paris) 2009;25:37-44
51. Wysoczynski M, Ratajczak MZ. Lung cancer secreted microvesicles: underappreciated modulators of microenvironment in expanding tumors. Int J Cancer 2009;125(7): 1595-1603

52. Angelucci A, D’Ascenzo S, Festuccia C, et al. Vesicleassociated urokinase plasminogen activator promotes invasion in prostate cancer cell lines. Clin Exp Metastasis 2000;18(2):163-170

53. Gesierich S, Berezovskiy I, Ryschich E, Zöller M. Systemic induction of the angiogenesis switch by the tetraspanin D6.1A/CO-029. Cancer Res 2006;66(14):7083-7094

54. Janowska-Wieczorek A, Wysoczynski M, Kijowski J, et al. Microvesicles derived from activated platelets induce metastasis and angiogenesis in lung cancer. Int J Cancer 2005; 113(5):752-760

55. Deregibus MC, Cantaluppi V, Calogero R, et al. Endothelial progenitor cell derived microvesicles activate an angiogenic program in endothelial cells by a horizontal transfer of mRNA. Blood 2007;110(7):2440-2448

56. Hong BS, Cho JH, Kim H, et al. Colorectal cancer cellderived microvesicles are enriched in cell cycle-related mRNAs that promote proliferation of endothelial cells. BMC Genomics 2009;10:556

57. Hood JL, Pan H, Lanza GM, Wickline SA; Consortium for Translational Research in Advanced Imaging and Nanomedicine (C-TRAIN). Paracrine induction of endothelium by tumor exosomes. Lab Invest 2009;89(11):1317-1328

58. Taraboletti G, D'Ascenzo S, Giusti I, et al. Bioavailability of VEGF in tumor-shed vesicles depends on vesicle burst induced by acidic pH. Neoplasia 2006;8(2):96-103

59. Hao S, Ye Z, Li F, et al. Epigenetic transfer of metastatic activity by uptake of highly metastatic B16 melanoma cellreleased exosomes. Exp Oncol 2006;28(2):126-131

60. Jung T, Castellana D, Klingbeil P, et al. CD44v6 dependence of premetastatic niche preparation by exosomes. Neoplasia 2009;11(10):1093-1105

61. Lima LG, Chammas R, Monteiro RQ, Moreira ME, Barcinski MA. Tumor-derived microvesicles modulate the establishment of metastatic melanoma in a phosphatidylserine-dependent manner. Cancer Lett 2009;283(2):168-175

62. Skog J, Würdinger $\mathrm{T}$, van Rijn $\mathrm{S}$, et al. Glioblastoma microvesicles transport RNA and proteins that promote tumour growth and provide diagnostic biomarkers. Nat Cell Biol 2008;10(12):1470-1476

63. Andreola G, Rivoltini L, Castelli C, et al. Induction of lymphocyte apoptosis by tumor cell secretion of FasLbearing microvesicles. J Exp Med 2002;195(10):1303-1316

64. Liu Y, Xiang X, Zhuang X, et al. Contribution of MyD88 to the tumor exosome-mediated induction of myeloid derived suppressor cells. Am J Pathol 2010;176(5):2490-2499

65. Iero $M$, Valenti $R$, Huber $V$, et al. Tumour-released exosomes and their implications in cancer immunity. Cell Death Differ 2008;15(1):80-88

66. Wolfers J, Lozier A, Raposo G, et al. Tumor-derived exosomes are a source of shared tumor rejection antigens for CTL cross-priming. Nat Med 2001;7(3):297-303

67. Koga K, Matsumoto K, Akiyoshi T, et al. Purification, characterization and biological significance of tumor-derived exosomes. Anticancer Res 2005;25(6A, 6A):3703-3707

68. Gelderman MP, Simak J. Flow cytometric analysis of cell membrane microparticles. Methods Mol Biol 2008;484: 79-93 
69. Morel O, Morel N, Freyssinet JM, Toti F. Platelet microparticles and vascular cells interactions: a checkpoint between the haemostatic and thrombotic responses. Platelets 2008;19(1):9-23

70. Lehmann BD, Paine MS, Brooks AM, et al. Senescenceassociated exosome release from human prostate cancer cells. Cancer Res 2008;68(19):7864-7871

71. Bianco F, Perrotta C, Novellino L, et al. Acid sphingomyelinase activity triggers microparticle release from glial cells. EMBO J 2009;28(8):1043-1054

72. Parolini I, Federici C, Raggi C, et al. Microenvironmental $\mathrm{pH}$ is a key factor for exosome traffic in tumor cells. J Biol Chem 2009;284(49):34211-34222

73. Park JE, Tan HS, Datta A, et al. Hypoxic tumor cell modulates its microenvironment to enhance angiogenic and metastatic potential by secretion of proteins and exosomes. Mol Cell Proteomics 2010;9:1085-1099

74. Yu JL, May L, Lhotak V, et al. Oncogenic events regulate tissue factor expression in colorectal cancer cells: implications for tumor progression and angiogenesis. Blood 2005; 105(4):1734-1741

75. Yu X, Harris SL, Levine AJ. The regulation of exosome secretion: a novel function of the p53 protein. Cancer Res 2006;66(9):4795-4801

76. Muralidharan-Chari V, Clancy J, Plou C, et al. ARF6regulated shedding of tumor cell-derived plasma membrane microvesicles. Curr Biol 2009;19(22):1875-1885

77. Valadi H, Ekström K, Bossios A, Sjöstrand M, Lee JJ, Lötvall JO. Exosome-mediated transfer of mRNAs and microRNAs is a novel mechanism of genetic exchange between cells. Nat Cell Biol 2007;9(6):654-659

78. Simpson RJ, Lim JW, Moritz RL, Mathivanan S. Exosomes: proteomic insights and diagnostic potential. Expert Rev Proteomics 2009;6(3):267-283

79. Sinauridze EI, Kireev DA, Popenko NY, et al. Platelet microparticle membranes have 50- to 100 -fold higher specific procoagulant activity than activated platelets. Thromb Haemost 2007;97(3):425-434

80. Krishnan L, Sprott GD. Archaeosome adjuvants: immunological capabilities and mechanism(s) of action. Vaccine 2008;26(17):2043-2055

81. Graner MW, Alzate O, Dechkovskaia AM, et al. Proteomic and immunologic analyses of brain tumor exosomes. FASEB J 2009;23(5):1541-1557

82. Heijnen HF, Schiel AE, Fijnheer R, Geuze HJ, Sixma JJ. Activated platelets release two types of membrane vesicles: microvesicles by surface shedding and exosomes derived from exocytosis of multivesicular bodies and alpha-granules. Blood 1999;94(11):3791-3799

83. Diamandis $P$, Sacher AG, Tyers M, Dirks PB. New drugs for brain tumors? Insights from chemical probing of neural stem cells. Med Hypotheses 2009;72(6):683-687

84. Bovellan M, Fritzsche M, Stevens C, Charras G. Deathassociated protein kinase (DAPK) and signal transduction: blebbing in programmed cell death. FEBS J 2010;277(1): 58-65

85. Vikkula M, Boon LM, Carraway KLIII, et al. Vascular dysmorphogenesis caused by an activating mutation in the receptor tyrosine kinase TIE2. Cell 1996;87(7):11811190

86. Ehnfors J, Kost-Alimova M, Persson NL, et al. Horizontal transfer of tumor DNA to endothelial cells in vivo. Cell Death Differ 2009;16(5):749-757
87. Bergsmedh A, Szeles A, Henriksson M, et al. Horizontal transfer of oncogenes by uptake of apoptotic bodies. Proc Natl Acad Sci U S A 2001;98(11):6407-6411

88. Orozco AF, Lewis DE. Flow cytometric analysis of circulating microparticles in plasma. Cytometry A 2010;77(6):502-514

89. Simak J, Gelderman MP. Cell membrane microparticles in blood and blood products: potentially pathogenic agents and diagnostic markers. Transfus Med Rev 2006;20(1):1-26

90. Bianco F, Pravettoni E, Colombo A, et al. Astrocytederived ATP induces vesicle shedding and IL-1 beta release from microglia. J Immunol 2005;174(11):7268-7277

91. Schiera G, Proia P, Alberti C, Mineo M, Savettieri G, Di Liegro I. Neurons produce FGF2 and VEGF and secrete them at least in part by shedding extracellular vesicles. J Cell Mol Med 2007;11(6):1384-1394

92. Mause SF, von Hundelshausen P, Zernecke A, Koenen RR, Weber C. Platelet microparticles: a transcellular delivery system for RANTES promoting monocyte recruitment on endothelium. Arterioscler Thromb Vasc Biol 2005;25(7): 1512-1518

93. Bevers EM, Williamson PL. Phospholipid scramblase: an update. FEBS Lett 2010;584(13):2724-2730

94. Taylor RC, Cullen SP, Martin SJ. Apoptosis: controlled demolition at the cellular level. Nat Rev Mol Cell Biol 2008;9(3):231-241

95. Charras GT, Yarrow JC, Horton MA, Mahadevan L, Mitchison TJ. Non-equilibration of hydrostatic pressure in blebbing cells. Nature 2005;435(7040):365-369

96. Tinevez JY, Schulze U, Salbreux G, Roensch J, Joanny JF, Paluch E. Role of cortical tension in bleb growth. Proc Natl Acad Sci U S A 2009;106(44):18581-18586

97. Zimmerberg J, Kozlov MM. How proteins produce cellular membrane curvature. Nat Rev Mol Cell Biol 2006;7(1):9-19

98. Toth B, Nikolajek K, Rank A, et al. Gender-specific and menstrual cycle dependent differences in circulating microparticles. Platelets 2007;18(7):515-521

99. Madden LA, Vince RV, Sandström ME, Taylor L, McNaughton L, Laden G. Microparticle-associated vascular adhesion molecule- 1 and tissue factor follow a circadian rhythm in healthy human subjects. Thromb Haemost 2008; 99(5):909-915

100. Zwaal RF, Comfurius P, Bevers EM. Scott syndrome, a bleeding disorder caused by defective scrambling of membrane phospholipids. Biochim Biophys Acta 2004;1636(2-3): 119-128

101. Zhou Q, Zhao J, Wiedmer T, Sims PJ. Normal hemostasis but defective hematopoietic response to growth factors in mice deficient in phospholipid scramblase 1. Blood 2002;99(11):4030-4038

102. Rak J, Yu JL, Luyendyk J, Mackman N. Oncogenes, Trousseau syndrome, and cancer-related changes in the coagulome of mice and humans. Cancer Res 2006;66(22): 10643-10646

103. Huang X, Bennett M, Thorpe PE. A monoclonal antibody that binds anionic phospholipids on tumor blood vessels enhances the antitumor effect of docetaxel on human breast tumors in mice. Cancer Res 2005;65(10):4408-4416

104. Trajkovic K, Hsu C, Chiantia S, et al. Ceramide triggers budding of exosome vesicles into multivesicular endosomes. Science 2008;319(5867):1244-1247

105. Murphy JE, Padilla BE, Hasdemir B, Cottrell GS, Bunnett NW. Endosomes: a legitimate platform for the signaling train. Proc Natl Acad Sci U S A 2009;106(42):17615-17622 
106. Hegmans JP, Gerber PJ, Lambrecht BN. Exosomes. Methods Mol Biol 2008;484:97-109

107. Zöller M. Tetraspanins: push and pull in suppressing and promoting metastasis. Nat Rev Cancer 2009;9(1):40-55

108. Poliakov A, Spilman M, Dokland T, Amling CL, Mobley JA. Structural heterogeneity and protein composition of exosome-like vesicles (prostasomes) in human semen. Prostate 2009;69(2):159-167

109. Sanderson MP, Keller S, Alonso A, Riedle S, Dempsey PJ, Altevogt P. Generation of novel, secreted epidermal growth factor receptor (EGFR/ErbB1) isoforms via metalloprotease-dependent ectodomain shedding and exosome secretion. J Cell Biochem 2008;103(6):1783-1797

110. Milsom CC, Yu JL, Mackman N, et al. Tissue factor regulation by epidermal growth factor receptor and epithelialto-mesenchymal transitions: effect on tumor initiation and angiogenesis. Cancer Res 2008;68(24):10068-10076

111. Marzesco AM, Janich $\mathrm{P}$, Wilsch-Bräuninger $\mathrm{M}$, et al. Release of extracellular membrane particles carrying the stem cell marker prominin-1 (CD133) from neural progenitors and other epithelial cells. J Cell Sci 2005;118(Pt 13):28492858

112. Hron G, Kollars M, Weber H, et al. Tissue factor-positive microparticles: cellular origin and association with coagulation activation in patients with colorectal cancer. Thromb Haemost 2007;97(1):119-123

113. Mack M, Kleinschmidt A, Brühl H, et al. Transfer of the chemokine receptor CCR5 between cells by membranederived microparticles: a mechanism for cellular human immunodeficiency virus 1 infection. Nat Med 2000;6(7): 769-775

114. Iwamura M, di Sant'Agnese PA, Wu G, et al. Immunohistochemical localization of parathyroid hormone-related protein in human prostate cancer. Cancer Res 1993;53(8): 1724-1726

115. Monleón I, Martínez-Lorenzo MJ, Monteagudo L, et al. Differential secretion of Fas ligand- or APO2 ligand/TNFrelated apoptosis-inducing ligand-carrying microvesicles during activation-induced death of human $\mathrm{T}$ cells. J Immunol 2001;167(12):6736-6744

116. Kim JW, Wieckowski E, Taylor DD, Reichert TE, Watkins S, Whiteside TL. Fas ligand-positive membranous vesicles isolated from sera of patients with oral cancer induce apoptosis of activated T lymphocytes. Clin Cancer Res 2005;11(3):1010-1020

117. Huber V, Fais S, Iero M, et al. Human colorectal cancer cells induce $\mathrm{T}$-cell death through release of proapoptotic microvesicles: role in immune escape. Gastroenterology 2005;128(7):1796-1804

118. Greco V, Hannus M, Eaton S. Argosomes: a potential vehicle for the spread of morphogens through epithelia. Cell 2001;106(5):633-645

119. Reya T, Clevers H. Wnt signalling in stem cells and cancer. Nature 2005;434(7035):843-850

120. Taipale J, Beachy PA. The Hedgehog and Wnt signalling pathways in cancer. Nature 2001;411(6835):349-354

121. Martínez MC, Larbret F, Zobairi F, et al. Transfer of differentiation signal by membrane microvesicles harboring hedgehog morphogens. Blood 2006;108(9): 3012-3020

122. Morel O, Toti F, Morel N, Freyssinet JM. Microparticles in endothelial cell and vascular homeostasis: are they really noxious? Haematologica 2009;94(3):313-317
123. Korkut C, Ataman B, Ramachandran P, et al. Transsynaptic transmission of vesicular Wnt signals through Evi/ Wntless. Cell 2009;139(2):393-404

124. Poupot M, Fournié JJ. Spontaneous membrane transfer through homotypic synapses between lymphoma cells. J Immunol 2003;171(5):2517-2523

125. Dolo V, Ginestra $A$, Cassarà $D$, et al. Selective localization of matrix metalloproteinase 9 , beta1 integrins, and human lymphocyte antigen class I molecules on membrane vesicles shed by $8701-\mathrm{BC}$ breast carcinoma cells. Cancer Res 1998;58(19):4468-4474

126. Barry OP, Pratico D, Lawson JA, FitzGerald GA. Transcellular activation of platelets and endothelial cells by bioactive lipids in platelet microparticles. J Clin Invest 1997; 99(9):2118-2127

127. Rak J, Yu JL, Klement G, Kerbel RS. Oncogenes and angiogenesis: signaling three-dimensional tumor growth. J Investig Dermatol Symp Proc 2000;5(1):24-33

128. Yu J, May L, Milsom C, et al. Contribution of host-derived tissue factor to tumor neovascularization. Arterioscler Thromb Vasc Biol 2008;28(11):1975-1981

129. Falati S, Liu $Q_{2}$ Gross $P$, et al. Accumulation of tissue factor into developing thrombi in vivo is dependent upon microparticle $\mathrm{P}$-selectin glycoprotein ligand 1 and platelet $\mathrm{P}$ selectin. J Exp Med 2003;197(11):1585-1598

130. Landsverk T, Trevella W, Nicander L. Transfer of carbonic anhydrase-positive particles from the follicleassociated epithelium to lymphocytes of Peyer's patches in foetal sheep and lambs. Cell Tissue Res 1990;261(2): 239-247

131. Liu R, Klich I, Ratajczak J, Ratajczak MZ, Zuba-Surma EK. Erythrocyte-derived microvesicles may transfer phosphatidylserine to the surface of nucleated cells and falsely 'mark' them as apoptotic. Eur J Haematol 2009;83(3): 220-229

132. Milsom C, Magnus N, Meehan B, Al-Nedawi K, Garnier D, Rak J. Tissue factor and cancer stem cells: is there a linkage? Arterioscler Thromb Vasc Biol 2009;29(12):20052014

133. Delves GH, Stewart AB, Cooper AJ, Lwaleed BA. Prostasomes, angiogenesis, and tissue factor. Semin Thromb Hemost 2007;33(1):75-79

134. Simpson RJ, Jensen SS, Lim JW. Proteomic profiling of exosomes: current perspectives. Proteomics 2008;8(19):40834099

135. Banfi C, Brioschi M, Barcella S, et al. Tissue factor induction by protease-activated receptor 1 requires intact caveolin-enriched membrane microdomains in human endothelial cells. J Thromb Haemost 2007;5(12):24372444

136. Mathivanan S, Lim JW, Tauro BJ, Ji H, Moritz RL, Simpson RJ. Proteomics analysis of A33 immunoaffinitypurified exosomes released from the human colon tumor cell line LIM1215 reveals a tissue-specific protein signature. Mol Cell Proteomics 2010;9(2):197-208

137. Choi DS, Lee JM, Park GW, et al. Proteomic analysis of microvesicles derived from human colorectal cancer cells. J Proteome Res 2007;6(12):4646-4655

138. Chen C, Skog J, Hsu CH, et al. Microfluidic isolation and transcriptome analysis of serum microvesicles. Lab Chip 2010;10(4):505-511

139. Thomas GM, Panicot-Dubois L, Lacroix R, Dignat-George F, Lombardo D, Dubois C. Cancer cell-derived micro- 
particles bearing $\mathrm{P}$-selectin glycoprotein ligand 1 accelerate thrombus formation in vivo. J Exp Med 2009;206(9):19131927

140. Gross PL, Furie BC, Merrill-Skoloff G, Chou J, Furie B. Leukocyte-versus microparticle-mediated tissue factor transfer during arteriolar thrombus development. J Leukoc Biol 2005;78(6):1318-1326

141. Zhou Z. New phosphatidylserine receptors: clearance of apoptotic cells and more. Dev Cell 2007;13(6):759-760

142. Park D, Tosello-Trampont AC, Elliott MR, et al. BAI1 is an engulfment receptor for apoptotic cells upstream of the ELMO/Dock180/Rac module. Nature 2007;450(7168):430 434

143. Nishimori $H$, Shiratsuchi $T$, Urano $T$, et al. A novel brainspecific p53-target gene, BAI1, containing thrombospondin type 1 repeats inhibits experimental angiogenesis. Oncogene 1997;15(18):2145-2150

144. McMahon HT, Kozlov MM, Martens S. Membrane curvature in synaptic vesicle fusion and beyond. Cell 2010; 140(5):601-605

145. Key NS, Chantrathammachart P, Moody PW, Chang J-Y. Membrane microparticles in VTE and cancer. Thromb Res 2010;125(Suppl 2):S80-S83

146. Zwicker JI. Predictive value of tissue factor bearing microparticles in cancer associated thrombosis. Thromb Res 2010;125(Suppl 2):S89-S91

147. Castellana D, Toti F, Freyssinet JM. Membrane microvesicles: macromessengers in cancer disease and progression. Thromb Res 2010;125(Suppl 2):S84-S88

148. Falanga A. Thrombophilia in cancer. Semin Thromb Hemost 2005;31(1):104-110

149. Rickles FR. Mechanisms of cancer-induced thrombosis in cancer. Pathophysiol Haemost Thromb 2006;35 (1-2):103-110

150. Lee AY. Cancer and thromboembolic disease: pathogenic mechanisms. Cancer Treat Rev 2002;28(3):137-140

151. Buller HR, van Doormaal FF, van Sluis GL, Kamphuisen PW. Cancer and thrombosis: from molecular mechanisms to clinical presentations. J Thromb Haemost 2007;5(Suppl 1): 246-254

152. Trousseau A. Phlegmasia alba dolens. 2nd ed. Clinique Medicale de L'Hotel-Dieu de Paris. Paris, France: Bailliere; 1865:654-712

153. Khorana AA, Francis CW, Menzies KE, et al. Plasma tissue factor may be predictive of venous thromboembolism in pancreatic cancer. J Thromb Haemost 2008;6(11): 1983-1985

154. Boccaccio C, Sabatino G, Medico E, et al. The MET oncogene drives a genetic programme linking cancer to haemostasis. Nature 2005;434(7031):396-400

155. Rak J, Klement G. Impact of oncogenes and tumor suppressor genes on deregulation of hemostasis and angiogenesis in cancer. Cancer Metastasis Rev 2000;19(1-2): 93-96

156. Milsom C, Anderson GM, Weitz JI, Rak J. Elevated tissue factor procoagulant activity in CD133-positive cancer cells. J Thromb Haemost 2007;5(12):2550-2552

157. Tallman MS, Lefebvre P, Baine RM, et al. Effects of alltrans retinoic acid or chemotherapy on the molecular regulation of systemic blood coagulation and fibrinolysis in patients with acute promyelocytic leukemia. J Thromb Haemost 2004;2(8):1341-1350
158. Russo L, Mandala M, Marchetti A, et al. Loss of angiogenic activity and improvement of hemostatic variables in patients with gastrointestinal stromal tumors (GIST) under imatinib therapy: a biological evaluation [abstract]. Thromb Res 2010;125:S175

159. Giesen PL, Rauch U, Bohrmann B, et al. Blood-borne tissue factor: another view of thrombosis. Proc Natl Acad Sci U S A 1999;96(5):2311-2315

160. Rauch U, Antoniak S. Tissue factor-positive microparticles in blood associated with coagulopathy in cancer. Thromb Haemost 2007;97(1):9-10

161. Contrino J, Hair G, Kreutzer DL, Rickles FR. In situ detection of tissue factor in vascular endothelial cells: correlation with the malignant phenotype of human breast disease. Nat Med 1996;2(2):209-215

162. Rak J, Milsom C, Yu J. Tissue factor in cancer. Curr Opin Hematol 2008;15(5):522-528

163. Kuypers FA, Larkin SK, Emeis JJ, Allison AC. Interaction of an annexin $\mathrm{V}$ homodimer (Diannexin) with phosphatidylserine on cell surfaces and consequent antithrombotic activity. Thromb Haemost 2007;97(3):478-486

164. Lacroix R, Sabatier F, Mialhe A, et al. Activation of plasminogen into plasmin at the surface of endothelial microparticles: a mechanism that modulates angiogenic properties of endothelial progenitor cells in vitro. Blood 2007;110(7):2432-2439

165. Sabatier F, Camoin-Jau L, Anfosso F, Sampol J, DignatGeorge F. Circulating endothelial cells, microparticles and progenitors: key players towards the definition of vascular competence. J Cell Mol Med 2009;13(3):454-471

166. Kim CW, Lee HM, Lee TH, Kang C, Kleinman HK, Gho YS. Extracellular membrane vesicles from tumor cells promote angiogenesis via sphingomyelin. Cancer Res 2002; 62(21):6312-6317

167. Kim HK, Song KS, Chung JH, Lee KR, Lee SN. Platelet microparticles induce angiogenesis in vitro. $\mathrm{Br} \mathrm{J}$ Haematol 2004;124(3):376-384

168. Rhee JS, Black M, Schubert U, et al. The functional role of blood platelet components in angiogenesis. Thromb Haemost 2004;92(2):394-402

169. Aoki N, Yokoyama R, Asai N, et al. Adipocyte-derived microvesicles are associated with multiple angiogenic factors and induce angiogenesis in vivo and in vitro. Endocrinology 2010;151(6):2567-2576

170. Smalheiser NR. Do neural cells communicate with endothelial cells via secretory exosomes and microvesicles? Cardiovasc Psychiatry Neurol 2009;August 3 (Epub ahead of print)

171. Folkman J. Tumor angiogenesis: therapeutic implications. N Engl J Med 1971;285(21):1182-1186

172. Folkman J. Angiogenesis: an organizing principle for drug discovery?. Nat Rev Drug Discov 2007;6(4):273-286

173. Ferrara N, Hillan KJ, Gerber HP, Novotny W. Discovery and development of bevacizumab, an anti-VEGF antibody for treating cancer. Nat Rev Drug Discov 2004;3(5): 391-400

174. Browder T, Folkman J, Pirie-Shepherd S. The hemostatic system as a regulator of angiogenesis. J Biol Chem 2000; 275(3):1521-1524

175. Zangari M, Fink LM, Elice F, Zhan F, Adcock DM, Tricot GJ. Thrombotic events in patients with cancer receiving antiangiogenesis agents. J Clin Oncol 2009;27(29):48654873 
176. Folkman J, Kalluri R. Tumor angiogenesis. In: Kufe DW, Pollock RE, Weichselbaum RR, et al, eds. Cancer Medicine. Hamilton, Ontario, Canada: BC Decker; 2003:161-194

177. Carmeliet P. Mechanisms of angiogenesis and arteriogenesis. Nat Med 2000;6(4):389-395

178. Kerbel RS. Tumor angiogenesis. N Engl J Med 2008; 358(19):2039-2049

179. Carmeliet P, De Smet F, Loges S, Mazzone M. Branching morphogenesis and antiangiogenesis candidates: tip cells lead the way. Nat Rev Clin Oncol 2009;6(6):315-326

180. Rak J, Kerbel RS. Oncogenes and tumor angiogenesis. In: Rak J, ed. Oncogene-Directed Therapies. Totowa, NJ: Humana Press; 2003:171-218

181. Pettersson A, Nagy JA, Brown LF, et al. Heterogeneity of the angiogenic response induced in different normal adult tissues by vascular permeability factor/vascular endothelial growth factor. Lab Invest 2000;80(1):99-115

182. Döme B, Hendrix MJ, Paku S, Tóvári J, Tímár J. Alternative vascularization mechanisms in cancer: pathology and therapeutic implications. Am J Pathol 2007;170(1):1-15

183. Pinedo HM, Verheul HM, D'Amato RJ, Folkman J. Involvement of platelets in tumour angiogenesis?. Lancet 1998;352(9142):1775-1777

184. Klement GL, Yip TT, Cassiola F, et al. Platelets actively sequester angiogenesis regulators. Blood 2009;113(12):28352842

185. Varon D, Shai E. Role of platelet-derived microparticles in angiogenesis and tumor progression. Discov Med 2009;8(43): 237-241

186. Thurston G, Noguera-Troise I, Yancopoulos GD. The Delta paradox: DLL4 blockade leads to more tumour vessels but less tumour growth. Nat Rev Cancer 2007;7(5):327-331

187. Dvorak HF, Dvorak AM, Manseau EJ, Wiberg L, Churchill WH. Fibrin gel investment associated with line 1 and line 10 solid tumor growth, angiogenesis, and fibroplasia in guinea pigs. Role of cellular immunity, myofibroblasts, microvascular damage, and infarction in line 1 tumor regression. J Natl Cancer Inst 1979;62(6):1459-1472

188. Rickles FR, Shoji M, Abe K. The role of the hemostatic system in tumor growth, metastasis, and angiogenesis: tissue factor is a bifunctional molecule capable of inducing both fibrin deposition and angiogenesis in cancer. Int J Hematol 2001;73(2):145-150

189. Belting M, Ahamed J, Ruf W. Signaling of the tissue factor coagulation pathway in angiogenesis and cancer. Arterioscler Thromb Vasc Biol 2005;25(8):1545-1550

190. Carmeliet P, Mackman N, Moons L, et al. Role of tissue factor in embryonic blood vessel development. Nature 1996; 383(6595):73-75

191. Holash J, Maisonpierre PC, Compton D, et al. Vessel cooption, regression, and growth in tumors mediated by angiopoietins and VEGF. Science 1999;284(5422):19941998

192. Millimaggi D, Mari M, D’Ascenzo S, et al. Tumor vesicleassociated CD147 modulates the angiogenic capability of endothelial cells. Neoplasia 2007;9(4):349-357

193. Brill A, Dashevsky O, Rivo J, Gozal Y, Varon D. Plateletderived microparticles induce angiogenesis and stimulate post-ischemic revascularization. Cardiovasc Res 2005;67(1): 30-38

194. Mostefai HA, Andriantsitohaina R, Martínez MC. Plasma membrane microparticles in angiogenesis: role in ischemic diseases and in cancer. Physiol Res 2008;57(3):311-320
195. Tsopanoglou NE, Maragoudakis ME. Role of thrombin in angiogenesis and tumor progression. Semin Thromb Hemost 2004;30(1):63-69

196. Furnari FB, Fenton T, Bachoo RM, et al. Malignant astrocytic glioma: genetics, biology, and paths to treatment. Genes Dev 2007;21(21):2683-2710

197. Candela ME, Geraci F, Turturici G, Taverna S, Albanese I, Sconzo G. Membrane vesicles containing matrix metalloproteinase- 9 and fibroblast growth factor- 2 are released into the extracellular space from mouse mesoangioblast stem cells. J Cell Physiol 2010;224(1):144-151

198. Taverna S, Ghersi G, Ginestra A, et al. Shedding of membrane vesicles mediates fibroblast growth factor-2 release from cells. J Biol Chem 2003;278(51):5191151919

199. Gibbings DJ, Ciaudo C, Erhardt M, et al. Multivesicular bodies associate with components of miRNA effector complexes and modulate miRNA activity. Nature Cell Biol 2009;11:1143-1149

200. Inui M, Martello G, Piccolo S. MicroRNA control of signal transduction. Nat Rev Mol Cell Biol 2010;11(4):252-263

201. Croce CM. Oncogenes and cancer. N Engl J Med 2008; 358(5):502-511

202. Gasser O, Schifferli JA. Activated polymorphonuclear neutrophils disseminate anti-inflammatory microparticles by ectocytosis. Blood 2004;104(8):2543-2548

203. Maass N, Hojo T, Zhang M, Sager R, Jonat W, Nagasaki K. Maspin - a novel protease inhibitor with tumor-suppressing activity in breast cancer. Acta Oncol 2000;39(8):931-934

204. Minetti G, Ciana A, Balduini C. Differential sorting of tyrosine kinases and phosphotyrosine phosphatases acting on band 3 during vesiculation of human erythrocytes. Biochem J 2004;377(Pt 2):489-497

205. Coren LV, Shatzer T, Ott DE. CD45 immunoaffinity depletion of vesicles from Jurkat $\mathrm{T}$ cells demonstrates that exosomes contain CD45: no evidence for a distinct exosome/ HIV-1 budding pathway. Retrovirology 2008;5:64

206. Sbai O, Ferhat L, Bernard A, et al. Vesicular trafficking and secretion of matrix metalloproteinases-2, -9 and tissue inhibitor of metalloproteinases- 1 in neuronal cells. Mol Cell Neurosci 2008;39(4):549-568

207. Pérez-Casal M, Downey C, Cutillas-Moreno B, Zuzel M, Fukudome K, Toh CH. Microparticle-associated endothelial protein $\mathrm{C}$ receptor and the induction of cytoprotective and anti-inflammatory effects. Haematologica 2009;94(3): 387-394

208. Baj-Krzyworzeka M, Majka M, Pratico D, et al. Plateletderived microparticles stimulate proliferation, survival, adhesion, and chemotaxis of hematopoietic cells. Exp Hematol 2002;30(5):450-459

209. Coussens LM, Werb Z. Inflammation and cancer. Nature 2002;420(6917):860-867

210. Kalas W, Yu JL, Milsom C, et al. Oncogenes and angiogenesis: down-regulation of thrombospondin-1 in normal fibroblasts exposed to factors from cancer cells harboring mutant ras. Cancer Res 2005;65(19):88788886

211. Heppner GH. Tumor heterogeneity. Cancer Res 1984;44(6): 2259-2265

212. Mellinghoff IK, Wang MY, Vivanco I, et al. Molecular determinants of the response of glioblastomas to EGFR kinase inhibitors. N Engl J Med 2005;353(19):20122024 